\title{
Hillslope-storage Boussinesq model for subsurface flow and variable source areas along complex hillslopes: 2. Intercomparison with a three-dimensional Richards equation model
}

\author{
Claudio Paniconi ${ }^{1}$ \\ Center for Advanced Studies, Research and Development in Sardinia, Cagliari, Italy
}

Peter A. Troch, E. Emiel van Loon, and Arno G. J. Hilberts

Hydrology and Quantitative Water Management Group, Department of Environmental Sciences, Wageningen University, Wageningen, Netherlands

Received 17 September 2002; revised 10 July 2003; accepted 6 August 2003; published 15 November 2003.

[1] The Boussinesq equation for subsurface flow in an idealized sloping aquifer of unit width has recently been extended to hillslopes of arbitrary geometry by incorporating the hillslope width function $w(x)$ into the governing equation, where $x$ is the flow distance along the length of the hillslope [Troch et al., 2003]. Introduction of a source/sink term $N$ allows simulation of storm-interstorm sequences in addition to drainage processes, while a function $S_{c}(x)$ representing the maximum subsurface water storage can be used to account for surface saturation response in variable source areas activated by the saturation excess mechanism of runoff generation. The model can thus simulate subsurface flow and storage dynamics for nonidealized (more realistic) hillslope configurations. In this paper we assess the behavior of this relatively simple, one-dimensional model in a series of intercomparison tests with a fully three-dimensional Richards equation model. Special attention is given to the discretization and setup of the boundary and initial conditions for seven representative hillslopes of uniform, convergent, and divergent plan shape. Drainage and recharge experiments are conducted on these hillslopes for both gentle $(5 \%)$ and steep $(30 \%)$ bedrock slope angles. The treatment and influence of the drainable porosity parameter are also considered, and for the uniform (idealized) hillslope case the impact of the unsaturated zone is examined by running simulations for different capillary fringe heights. In general terms, the intercomparison results show that the hillslope-storage Boussinesq model is able to capture the broad shapes of the storage and outflow profiles for all of the hillslope configurations. In specific terms, agreement with the Richards equation results varies according to the scenario being simulated. The best matches in outflow hydrographs were obtained for the drainage experiments, suggesting a greater influence of the unsaturated zone under recharge conditions due to transmission of water throughout the hillslope. In the spatiotemporal water table response a better match was observed for convergent than divergent hillslopes, and the bedrock slope angle was not found to greatly influence the quality of the agreement between the two models. On the basis of the intercomparison experiments we make some suggestions for further development and testing of the hillslope-storage model. INDEX TERMS: 1829 Hydrology: Groundwater hydrology; 1875 Hydrology: Unsaturated zone; 1894 Hydrology: Instruments and techniques; KEYWORDS: subsurface flow, hillslope drainage, Boussinesq equation, Richards equation, groundwater modeling, unsaturated zone

Citation: Paniconi, C., P. A. Troch, E. E. van Loon, and A. G. J. Hilberts, Hillslope-storage Boussinesq model for subsurface flow and variable source areas along complex hillslopes: 2 . Intercomparison with a three-dimensional Richards equation model, Water Resour. Res., 39(11), 1317, doi:10.1029/2002WR001730, 2003.

\footnotetext{
${ }^{1}$ Now at Institut National de la Recherche Scientifique, Center Eau, Terre et Environnement, Université du Québec, Sainte-Foy, Quebec, Canada.

Copyright 2003 by the American Geophysical Union. 0043-1397/03/2002WR001730\$09.00
}

\section{Introduction}

[2] Simple but physically realistic models capable of representing hydrologic processes at the hillslope and catchment scales are needed for reliable simulation of overland and subsurface flow [Hornberger and Boyer, 1995; Beven, 2001]. Such models should be able to handle the spatial and temporal variability of the atmospheric, 
topographic, geomorphologic, and soil characteristics that exert an important control on the dynamics of subsurface water storage and groundwater flow and on the timing and magnitude of surface runoff generation [e.g., Loague, 1988; Woods and Sivapalan, 1999; Grayson and Blöschl, 2000]. Many existing hillslope drainage models based on Dupuit-Forchheimer, Boussinesq, or kinematic wave theory provide useful and efficient solutions for idealized configurations (one-dimensional flow, unit-width hillslope, homogeneous soil, saturated conditions under a free surface boundary, simple endpoint boundary conditions, etc), but clearly these models cannot be considered realistic beyond their restricted base of assumptions. Simplicity is desirable because even at the hillslope scale practical application of, for example, a three-dimensional numerical Richards equation (RE) model is not always feasible. The difficulties here are both structural and computational: parameter identifiability problems that engender a mismatch between model complexity and the amount and accuracy of data which is normally available to parameterize, initialize, and calibrate such a model; and the fine spatiotemporal grids (and consequent high computer memory and CPU costs) needed to avoid numerical convergence problems and to accurately capture the dynamics of subsurface water drainage, infiltration, and redistribution during storm and interstorm periods.

[3] An equally urgent need is for a basis or framework that enables critical and objective assessment of existing and new hydrological models. Several initiatives have been undertaken recently at national and international levels to promote the establishment of benchmark tools and data sets, model intercomparison studies, and networks of experimental catchments and hillslopes. In the case of hillslope scale models of subsurface flow, intercomparison with physically based reference models applicable over a broad range of conditions, such as a 3-D numerical RE model, will identify the circumstances under which different models generate comparable responses. This can help in the assessment of any limitations in the hillslope model and in the formulation of possible improvements. The use of a reference model in a systematic study also contributes insights into the relative importance of different factors or parameters in the dynamics of subsurface flow. This latter approach is represented for instance by the investigations of Freeze [1972] (the role of soil, rainfall, and geomorphological factors, in particular profile curvature, on infiltration and runoff generation using Richards equation simulations of vertical cross sections of a hypothetical rectangular hillslope), Fipps and Skaggs [1989] (the influence of hillslope angle on drain flow rates and water table depths in the center regions of a sloping aquifer using a 2-D finite element RE model), Shamsai and Narasimhan [1991] (the relationship between the free surface and seepage face in unconfined aquifer flow and the validity of Dupuit-Forchheimer assumptions using a variably saturated transient flow model), Kim and Stricker [1996] (the impact of rainfall and soil heterogeneity on subsurface water storage dynamics using Monte Carlo simulations based on a 1-D RE model), and Ogden and Watts [2000] (functional relationships between rainfall rate and hillslope properties (soil depth, slope angle, hillslope length, and saturated conductivity) and the evolution of saturated source areas using a 2-D finite difference variably saturated numerical model). As examples of intercomparison tests involving two or more models, we can cite Sloan and Moore [1984] (1- and 2-D finite element Richards equation models, a kinematic wave model, and two simple storagedischarge models), Smith et al. [1993, 1999] (a 1-D numerical RE model and a simplified infiltration and redistribution model for complex soils and storm-interstorm events), Troch et al. [1993] (a 3-D finite element RE model and a distributed catchment water balance model based on Philip's infiltration equation, the time compression approximation, and a topographic index for saturation excess runoff prediction), Chen et al. [1994] (a 3-D finite difference RE model and two horizontally averaged Richards equation and GreenAmpt models for subsurface flow under heterogeneous conditions), Michaud and Sorooshian [1994] (spatially distributed and lumped versions of the SCS curve number model and a distributed model for kinematic channel flow routing coupled with an analytical 1-D Richards equationbased infiltration model), Wigmosta and Lettenmaier [1999] (the topographic index-based Topmodel, a quasi-3-D gridbased saturated subsurface flow model, and an analytically solved kinematic wave model), and Willgoose and Perera [2001] (a kinematic wave model and a steady state saturation excess runoff generation model based on commonly observed catchment geomorphological relationships).

[4] In this paper we run intercomparison experiments to assess the validity of a recently developed model [Troch et al., 2003] that reformulates Boussinesq's equation so as to extend it to nonidealized hillslopes. The reformulation is based on a methodology introduced by Fan and Bras [1998] for collapsing a three-dimensional soil mantle into a storage capacity profile. The resulting hillslope-storage Boussinesq (HSB) model allows for the computation of subsurface flow and saturation excess overland flow for hillslopes of arbitrary geometry (in plan and profile) and can handle spatially and temporally variable parameters (recharge, hydraulic properties, endpoint boundary conditions, slope angle) when solved numerically in its most general form. The model is simple in that it is based on Boussinesq's equation rather than Richards' equation (the nonlinear coefficients of an RE model introduce parameters that are difficult or costly to accurately measure) and is effectively one-dimensional rather than 3-D (the coordinate directions laterally and vertically perpendicular to the flow direction $x$ are subsumed into the width function $w(x)$ and the width-averaged water table height $\bar{h}(x, t)$ in the definition of the subsurface water storage $S(x, t)=f w \bar{h}$, where $f$ is the drainable porosity and $t$ is time). In analogy to the definition of $S$, a storage capacity function for subsurface water or soil moisture is also introduced, defined as $S_{c}(x)=$ $f w(x) \bar{d}(x)$ where $\bar{d}$ is the width-averaged soil depth. In sum, the width function, soil depth, and bedrock slope angle $i$ parameters in the HSB model can account for topographic and geomorphologic controls on subsurface flow dynamics and runoff generation, while atmospheric contributions in terms of effective rainfall recharge or evaporative losses are represented by a source/sink term $N(x, t)$, and the remaining parameters in the model (drainable porosity $f$ and hydraulic conductivity $k$ ) account for soil (pedologic and hydrogeologic) controls on flow in sloping aquifers.

[5] The main question we address in this paper is whether the relatively simple HSB model is able to simulate the characteristic response of flow in complex nonuniform 
Table 1. Parameter Values for the Intercomparison Simulations

\begin{tabular}{ll}
\hline \multicolumn{1}{c}{ Parameter } & \multicolumn{1}{c}{ Value } \\
\hline Saturated hydraulic conductivity $K_{s}$ & $2.8 \times 10^{-4} \mathrm{~m} / \mathrm{s}(\sim 1.0 \mathrm{~m} / \mathrm{hr})$ \\
Aquifer specific storage $S_{s}$ & $0.01 \mathrm{~m}^{-1}$ \\
Porosity $\phi\left(=\theta_{s}\right.$, saturated moisture content) & 0.30 \\
Soil hydraulic properties (equations (3) and $(4))$ & $\theta_{r}=0, \psi_{c}=-0.12 \mathrm{~m}, \beta=3.3$ \\
Soil depth $\bar{d}, \bar{d}_{z}$ & $2 \mathrm{~m}$ \\
Number of soil layers for 5\% slope angle & 20 \\
Soil layer thicknesses for 5\% slope angle & $0.06 \mathrm{~m}$ top 10 layers, $0.14 \mathrm{~m}$ bottom 10 layers \\
Number of soil layers for 30\% slope angle & 40 \\
Soil layer thicknesses for 30\% slope angle & $0.05 \mathrm{~m}$ all layers \\
Number of nodes in the 3-D grid & 29547 (20-layer grid), $57687(40-l a y e r$ grid) \\
Number of tetrahedral elements & 144000 (20-layer grid), 288000 (40-layer grid) \\
Range of time step sizes for RE (adaptive stepping) & {$\left[10^{-4}, 10^{4}\right] \mathrm{s}$} \\
HSB model spatial discretization & $0.5 \mathrm{~m}$ \\
HSB model temporal discretization & $3600 \mathrm{~s}(5 \%$ slope angle), $1800 \mathrm{~s}(30 \%$ slope angle) \\
\hline
\end{tabular}

hillslopes. A 3-D Richards equation model of variably saturated flow in porous media is used for the intercomparisons, and seven basic hillslopes representing convergent, uniform, and divergent plan shapes are analyzed for gentle (5\% slope angle) and steep (30\%) configurations subjected to free drainage and drainage under recharge. The primary focus of this paper is on the features introduced into Boussinesq's equation to derive the HSB model, and thus on assessing the HSB model's ability to capture the effects of atmospheric, topographic, and geomorphologic controls, in particular the influence of convergence/divergence on water storage profiles, variable source area dynamics, and outlet hydrographs. Some attention will also be devoted to examining the influence of soil properties, in particular the parameter representing the capillary fringe height, for the uniform hillslope case for which the HSB model reduces to the classical Boussinesq equation. Finally, we will discuss some of the issues in setting up a proper intercomparison between the HSB and RE models, and some of the numerical difficulties associated with a 3-D RE simulation as encountered in our tests.

\section{Description of the Models}

[6] We assess only the full version of the hillslopestorage Boussinesq model, given by equation (6) of Troch et al. [2003] and restated here for convenience:

$$
f \frac{\partial S}{\partial t}=\frac{k \cos i}{f} \frac{\partial}{\partial x}\left[\frac{S}{w}\left(\frac{\partial S}{\partial x}-\frac{S}{w} \frac{\partial w}{\partial x}\right)\right]+k \sin i \frac{\partial S}{\partial x}+f N w
$$

[7] The HSB model is compared to a fully three-dimensional model of hillslope subsurface flow that considers also the unsaturated zone and is described by Richards' equation

$$
\eta(\psi) \frac{\partial \psi}{\partial t}=\nabla \cdot\left(K_{s} K_{r}(\psi) \nabla(\psi+z)\right)
$$

where $\eta=S_{w} S_{s}+\theta_{s}\left(d S_{w} / d \psi\right)$ is the general storage term, $S_{w}$ is the water saturation defined as $\theta / \theta_{s}, \theta$ is the volumetric moisture content, $\theta_{s}$ is the saturated moisture content (which we consider equal to the porosity $\phi$ in this paper), $S_{s}$ is the aquifer specific storage coefficient, $\psi$ is pressure head, $z$ is the vertical coordinate (positive upward), and the hydraulic conductivity tensor is expressed as a product of the conductivity at saturation, $K_{s}$, and the relative conductivity, $K_{r}(\psi) . K_{s}$ corresponds to the hydraulic conductivity $k$ of the
HSB model. Note that with reference to the upslope coordinate direction $x$ defined for the HSB model, the coordinate direction along the hillslope for the RE model is $x \cos i$ (perpendicular to $z$ as implied in equation (2)).

[8] The RE model represented by equation (2) is highly nonlinear due to pressure head dependencies in the storage and conductivity terms, which we characterize in this paper using the Brooks-Corey relationships [Brooks and Corey, 1964]

$$
\begin{array}{cc}
S_{e}(\psi)=\left(\psi_{c} / \psi\right)^{\beta}, & \psi<\psi_{c} \\
S_{e}(\psi)=1, & \psi \geq \psi_{c} \\
K_{r}(\psi)=\left(\psi_{c} / \psi\right)^{2+3 \beta}, & \psi<\psi_{c} \\
K_{r}(\psi)=1, & \psi \geq \psi_{c}
\end{array}
$$

where $S_{e}$ is the effective saturation defined as $\left(\theta-\theta_{r}\right) /\left(\theta_{s}-\theta_{r}\right)$, $\theta_{r}$ is the residual moisture content, $\beta$ is a constant representing a pore size distribution index, and $\psi_{c}$ is a capillary length scale fitting parameter that for draining soils is related to the bubbling or air entry pressure head [Salvucci and Entekhabi, 1995] and that we will use here to represent the height of the capillary fringe.

[9] The RE model used in this work is the subsurface module of a coupled surface-subsurface numerical model [Bixio et al., 2000] based on a tetrahedral finite element discretization in space, a weighted finite difference scheme in time, and Newton or Picard iteration to resolve the nonlinearity [Paniconi and Putti, 1994]. The model can be applied to hillslopes and subcatchments of arbitrary geometry and topography, and handles heterogeneous parameters and boundary conditions, including atmospheric forcing and seepage faces.

\section{Experiment Design}

[10] The parameter values and other settings used for the RE and HSB model simulations discussed in this section are summarized in Table 1.

\subsection{Discretization}

[11] The HSB and RE models are intercompared for the seven hillslopes described by Troch et al. [2003], consisting 

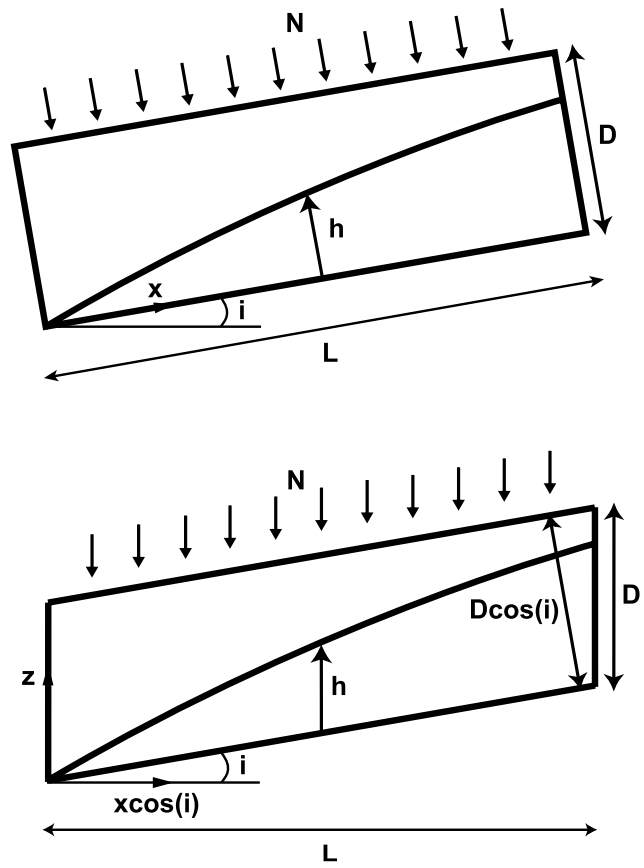

Figure 1. Sketch of the hillslope configurations and coordinate reference frames for an idealized unit-width hillslope with aquifer depth $D$, length $L$, water table height $h$, bedrock slope angle $i$, and imposed recharge flux $N$ as used for (top) the Boussinesq equation model and (bottom) the Richards equation model.

of three convergent, three divergent, and one uniform hillslope. Once generated for the HSB model, these seven hillslopes were discretized for the RE model, introducing some small variations to account for mathematical differences between the two models. Namely, whereas for the HSB model the hillslope length is $L=100 \mathrm{~m}$ and the soil depth, measured perpendicular to $x$, is $\bar{d}=2 \mathrm{~m}$, for the RE model the hillslope length $L_{x} \cos i=100 \mathrm{~m}$ and the soil depth $\overline{d_{z}}=2 \mathrm{~m}$ are measured in a horizontal/vertical Cartesian reference frame (Figure 1). Thus in terms of the Boussinesq/HSB reference frame, the RE hillslope has a length of $100 / \cos i$, or $104.4031 \mathrm{~m}$ for the $30 \%$ slope angle and $100.1249 \mathrm{~m}$ for the 5\% slope, and a depth of $2 \cos i$, or $1.9157 \mathrm{~m}$ for the $30 \%$ slope and $1.9975 \mathrm{~m}$ for the 5\% slope. Note however that the cross-sectional area (length * depth) for both the HSB and RE hillslopes is the same $\left(200 \mathrm{~m}^{2}\right)$, and therefore also the total volume of the hillslopes. The hillslope volumes are important in calibrating the HSB model's drainable porosity parameter, as described in section 3.3, and are given in Table 2. The slope width, which determines the hillslope volume given that the length and depth are kept fixed for the seven hillslopes, ranges from $50 \mathrm{~m}$ to $1.72 \mathrm{~m}$ with a maximum value at the crest for the convergent slopes and at the outlet for the divergent slopes (see Table 2). For the RE model the lateral coordinate $y$ is taken to be zero along the center or midline of each hillslope.

[12] There are two optional discretizations for the RE model hillslopes. The first would be to simulate precisely the same "tilted box" hillslope as the HSB model, but this is not possible with the RE model used in this work because the vertical discretization is derived by projecting straight downward the surface domain or shape, so that the lateral boundaries of the discretized hillslope aquifer are vertical rather than tilted. The second option, possible with our model and in some (but not all) respects more consistent with the HSB hillslopes than the discretization we used, would be to preserve the length and depth by setting $L_{x \cos i}=L \cos i$ and $\overline{d_{z}}=\bar{d} / \cos i$ to give horizontal and vertical dimensions of $95.7826 \mathrm{~m}$ and $2.0881 \mathrm{~m}$ respectively for the $30 \%$ slope and $99.8752 \mathrm{~m}$ and $2.0025 \mathrm{~m}$ for the $5 \%$ slope. Any differences in simulation results between this discretization and the one used are probably not significant, however, since the cross-sectional area is preserved as already noted and since the differences in length and depth are only $4.2 \%$ and $0.09 \%$ respectively for the $30 \%$ slope and much smaller for the 5\% slope.

[13] Each of the seven representative hillslopes was discretized for RE model simulation into 201 equally spaced nodes horizontally $\left(\Delta L_{x} \cos i=0.5 \mathrm{~m}\right)$ and 7 equally spaced nodes laterally (e.g., $\Delta y=8.33 \mathrm{~m}$ at crest to $\Delta y=0.287 \mathrm{~m}$ at outlet for the narrowest convergent hillslope). These $200 * 6$ rectangular elements were subdivided diagonally to yield a surface grid of 2400 triangles (Figure 2). As already mentioned this surface grid is projected vertically,

Table 2. Calibration of Drainable Porosity Parameter for Free Drainage Scenarios

\begin{tabular}{|c|c|c|c|c|c|c|c|c|c|c|c|c|}
\hline \multirow[b]{2}{*}{$\begin{array}{l}\text { Hillslope } \\
\text { Identifier }\end{array}$} & \multirow[b]{2}{*}{$\begin{array}{l}\text { Hillslope } \\
\text { Volume } \\
V_{h}, \mathrm{~m}^{3}\end{array}$} & \multirow[b]{2}{*}{$\begin{array}{c}\text { Hillslope } \\
\text { Crest } \\
\text { Width, } \\
\text { m }\end{array}$} & \multirow[b]{2}{*}{$\begin{array}{l}\text { Hillslope } \\
\text { Outlet } \\
\text { Width, } \\
\text { m }\end{array}$} & \multirow[b]{2}{*}{$\begin{array}{c}\text { Vol Water } \\
\text { at Time } 0 \\
\text { RE Model } \\
V_{w}, \mathrm{~m}^{3}\end{array}$} & \multicolumn{4}{|c|}{$5 \%$ Slope Angle } & \multicolumn{4}{|c|}{$30 \%$ Slope Angle } \\
\hline & & & & & $\begin{array}{l}\text { Cum Water } \\
\text { Drained } \\
\text { RE } \\
\text { Model } V_{c}\end{array}$ & $\begin{array}{c}\text { Calibrated } \\
\qquad f^{\text {a }}\end{array}$ & $\begin{array}{c}\text { Cum Water } \\
\text { Drained HSB } \\
\text { Model } \\
V_{H S B}^{\mathrm{b}}\end{array}$ & $\begin{array}{c}\text { Corrected } \\
V_{H S B}^{c}\end{array}$ & $\begin{array}{l}\text { Cum Water } \\
\text { Drained } \\
\text { RE } \\
\text { Model } V_{c}\end{array}$ & $\begin{array}{c}\text { Calibrated } \\
f^{\text {a }}\end{array}$ & $\begin{array}{c}\text { Cum Water } \\
\text { Drained HSB } \\
\text { Model } \\
V_{H S B}{ }^{\circ}\end{array}$ & $\begin{array}{c}\text { Corrected } \\
V_{H S B}^{c}\end{array}$ \\
\hline $\mathrm{a}$ & 4991 & 50.0 & 1.72 & 433 & 415 & 0.288 & 301 & 435 & $426^{\mathrm{d}}$ & 0.295 & $300^{\mathrm{e}}$ & 434 \\
\hline $\mathrm{b}$ & 4320 & 50.0 & 6.74 & 374 & 360 & 0.289 & 261 & 377 & 372 & 0.298 & 260 & 376 \\
\hline $\mathrm{c}$ & 2819 & 50.0 & 3.87 & 244 & 235 & 0.289 & 171 & 247 & 241 & 0.296 & 170 & 246 \\
\hline d & 1293 & 1.72 & 50.0 & 112 & 108 & 0.289 & 77 & 111 & 110 & 0.295 & 74 & 107 \\
\hline e & 4320 & 6.74 & 50.0 & 374 & 360 & 0.289 & 258 & 373 & 371 & 0.298 & 255 & 368 \\
\hline$f$ & 4771 & 3.87 & 50.0 & 413 & 397 & 0.288 & 285 & 412 & 410 & 0.298 & 282 & 407 \\
\hline Uniform & 10000 & 50.0 & 50.0 & 866 & 832 & 0.288 & 600 & 867 & 862 & 0.299 & 597 & 863 \\
\hline
\end{tabular}

${ }^{\mathrm{a}} \phi V_{c} / V_{w^{*}}$

${ }^{\mathrm{b}}$ Using $f=0.3$ for all hillslopes.

${ }^{\mathrm{c}} V_{H S B} * 1.445$, where $1.445=0.578 / 0.40,0.578$ is the equivalent depth of soil water at time zero for the RE model $\left(\bar{d} V_{w} /\left(\phi V_{h}\right)\right)$, and 0.40 is depth of soil water at time 0 for the HSB model.

${ }^{\mathrm{d}}$ Includes $102 \mathrm{~m}^{3}$ of surface runoff.

Includes $55 \mathrm{~m}^{3}$ of surface runoff. 

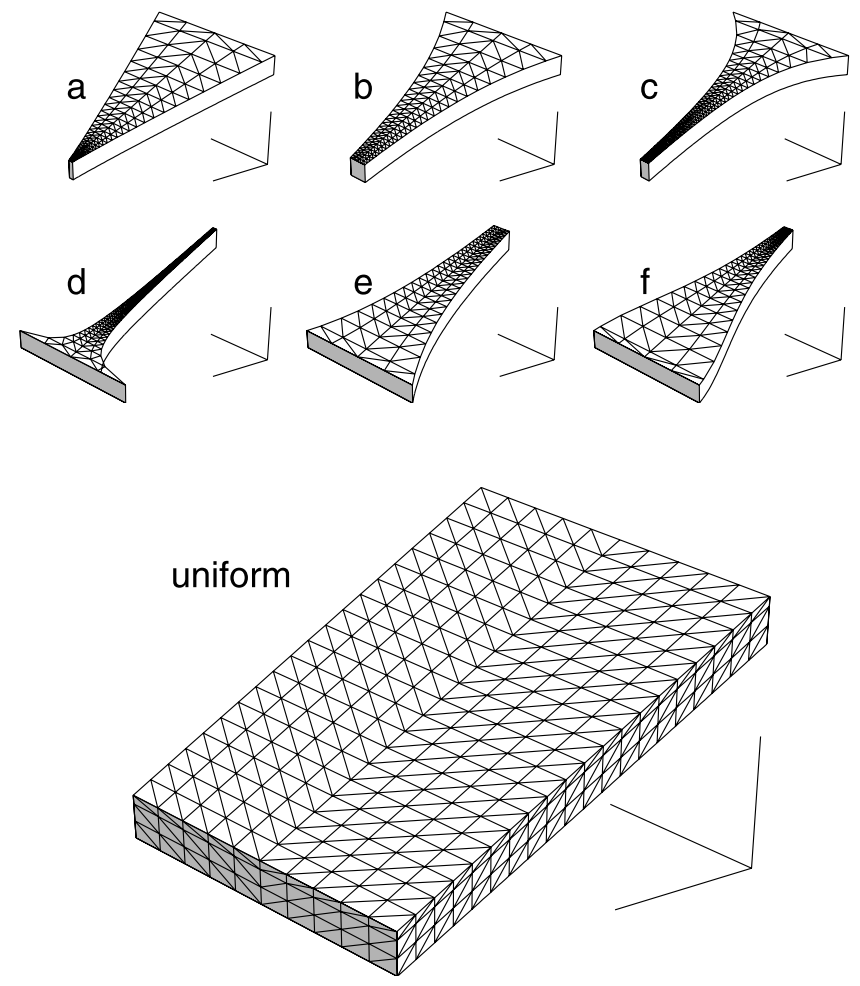

Figure 2. Three-dimensional view of the three convergent (a, b, and c), three divergent ( $d$, e, and $\mathrm{f}$ ), and uniform hillslopes used in the intercomparison tests. The triangular surface grid and the vertical discretization used for the Richards equation model are shown here at coarser resolution than that used in the simulations.

with each layer discretized into 7200 tetrahedral elements (3 tetrahedra out of each prism). For our simulations we used a 20 -layer discretization for the 5\% hillslopes, yielding a 3-D grid with 144000 tetrahedral elements and 29547 nodes, and a 40 -layer discretization for the $30 \%$ hillslopes, producing 288000 tetrahedra and 57687 nodes. The finer grid used for the steeper hillslopes was needed to improve numerical accuracy and reduce the oscillations or wiggles in the resulting water table profiles and outflow hydrographs, as will be shown later.

\subsection{Initial and Boundary Conditions}

[14] We impose initial conditions of equal "water table height" between the HSB and RE models for all the hillslope simulations, since we consider this to be the most reasonable configuration to intercompare the Richards and HSB models and to assess the importance of the unsaturated zone under different scenarios. The initial water storage for the HSB model is set to $20 \%$ of capacity $S_{c}$, distributed uniformly over the hillslope and so yielding a widthaveraged or midline water table height $\bar{h}(x, 0)$ of $0.4 \mathrm{~m}$, measured perpendicular to the bedrock slope. For the Richards equation model the initial pressure head distribution is vertically hydrostatic with the water table $(\psi=0)$ also positioned at $0.4 \mathrm{~m}$ above the bedrock (but measured vertically), giving a pressure head of $-1.6 \mathrm{~m}$ at the surface and $0.4 \mathrm{~m}$ for the nodes along the base of the hillslope. These initial conditions were selected instead of fully saturated conditions (for the drainage scenario) in order to avoid occurrence of excessive surface runoff. The zone of saturation defined by the water table height for the RE model of course does not include the capillary fringe, also fully saturated but above the water table (i.e., in tension). We will come back to this point later.

[15] The hillslope divide at the slope crest is treated as a no-flow boundary for the RE and HSB models, and additionally for the RE model the lateral divides and the bottom layer are also assigned a zero-flux condition. At the outlet $x=0$ the water storage $S(0, t)$ for the HSB model is assigned a fixed value of zero (Dirichlet boundary condition), while for the RE model the seven outlet nodes at the bottom layer form a constant head boundary of zero pressure head and the nodes above these seven along the outlet face have a noflow condition imposed.

[16] In the outflow hydrograph and water storage profile results that will be shown, the RE model outflow is the sum of Darcy fluxes calculated over the seven Dirichlet nodes along the bottom layer, and corresponds to the volumetric discharge flux $Q$ at $x=0$ computed from the HSB model [Troch et al., 2003, equation (5)], both of which are normalized to dimension $[\mathrm{L} / \mathrm{T}]$ through division by the surface area of each hillslope. The storage results are plotted as relative (dimensionless) storage values, calculated for the HSB model as $S(x, t) / S_{c}(x)\left(\left[\mathrm{L}^{2} / \mathrm{L}^{2}\right]\right)$ and for the RE model as water table height divided by soil depth $([\mathrm{L} / \mathrm{L}])$, where the water table position is computed for each node point $x$ along the midline $y=0$ by linear interpolation between the first two vertical nodes, starting from the bottom of the hillslope, for which the pressure head $\psi$ switches from a positive to a negative value. Given that $\bar{h}$ for the HSB model is defined as a width-averaged groundwater elevation, a width average should also be used for the RE model rather than the single point at $y=0$, but we found little difference between these two measures when we compared them for one of the hillslopes [Hilberts and Paniconi, 2001].

[17] It should be remarked that since the RE model uses a finite element discretization with standard linear basis functions, computed flux values, which at Dirichlet boundaries are "back calculated" after resolving the system equations for the unknown nodal pressure head values, are prone to inaccuracies (oscillations or wiggles and other numerical errors) due to the use of node rather than volumebased computations and to the piecewise continuity of any derivative terms in the model. Such behavior can be especially problematic when flux values are high and rapidly changing, for instance across an outflow boundary at the early times of a drainage simulation when the water table is instantaneously dropped to zero to satisfy an imposed Dirichlet boundary condition. In the experiment design we have tried to minimize these problems by using a fine grid discretization. For example, Figure 3 shows the storage and outflow profiles obtained with the RE model using 20-layer and 40-layer vertical discretizations for the free drainage experiment on the uniform 30\% hillslope. Although the timing and magnitudes of the simulation results shown in Figure 3 are comparable for the two cases, it is apparent that the solution for the coarser grid contains inaccuracies that show up as wiggles and an inability to capture the sharp front of the water table profile near the outlet. These numerical errors are artifacts that can be eliminated with a fine enough grid (the 40-layer solution 


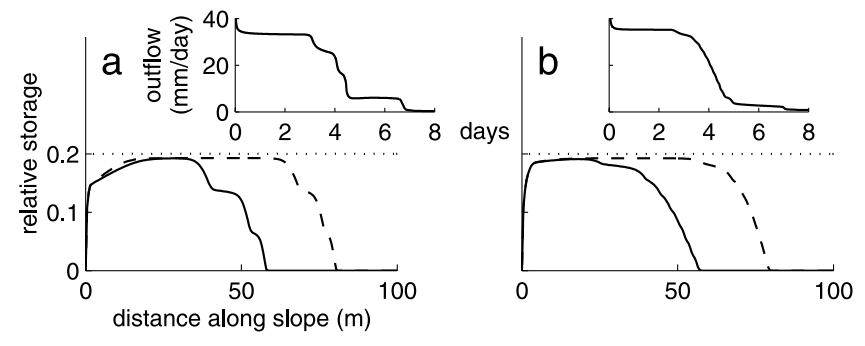

Figure 3. Comparison of the RE model simulation results using (a) a 20-layer and (b) a 40-layer vertical discretization. Shown are the relative storage profiles along the hillslope and the normalized subsurface flow rates $(\mathrm{mm} /$ day) at the outlet during the drainage run for the uniform hillslope at a 30\% slope angle. For the relative storage plots, dotted line is initial time, $t=0$; dashed line is $t=1$ day; and solid line is $t=2$ days.

is much smoother yet small oscillations are still visible) and other techniques, but this can add significantly to the cost of the RE simulation not only because the problem size (number of nodes) increases, but also because a finer spatial grid also normally incurs smaller time steps and slower convergence in the nonlinear and linear iterative solvers [Paniconi and Putti, 1994]. As already mentioned, for our intercomparison experiments we found that the 20-layer vertical discretization was sufficiently accurate for the $5 \%$ hillslopes while the 40-layer grid was adopted for the steeper 30\% slope angle simulations. We will make further remarks on the numerical behavior of the RE model in the discussion of the intercomparison results.

[18] For the rainfall recharge scenario, the water input to the hillslopes is introduced via a source term $N(x, t)$ in the HSB model and via a surface boundary condition for the RE model. For both models the recharge rate imposed is $10 \mathrm{~mm} /$ day $\left(1.157 \times 10^{-7} \mathrm{~m} / \mathrm{s}\right)$, applied perpendicular to the bedrock reference plain in the case of HSB and vertically for the RE model (Figure 1). Since we have $L=100 \mathrm{~m}$ for the HSB hillslopes and $L_{x \cos i}=100 \mathrm{~m}$ for the RE hillslopes, the volume of water introduced into the hillslopes by recharge is identical for the two models, just as the hillslope volumes were shown to be equal.

\subsection{Model Parameters}

[19] For the seven hillslopes the following parameter values corresponding to a sandy loam soil [Bras, 1990] were used for the RE model (Table 1): $K_{s}=2.8 \times 10^{-4} \mathrm{~m} / \mathrm{s}$, $\theta_{s}=0.30, \theta_{r}=0, \beta=3.3, \psi_{c}=-0.12 \mathrm{~m}$, and $S_{s}=0.01 \mathrm{~m}^{-1}$. Additionally, for the uniform hillslope we will comment on the influence of the capillary fringe component of the unsaturated zone, increasing this height from $0.12 \mathrm{~m}$ to $0.25 \mathrm{~m}$ and decreasing it to $0.01 \mathrm{~m}$ (Figure 4). For the HSB model, the hydraulic conductivity $k$ has the same meaning as the saturated conductivity $K_{s}$ when this latter parameter is treated as a scalar (isotropic porous medium) as we do in this paper, thus $k=K_{s}$ was used for all test cases.

[20] The drainable porosity $f$ does not have a direct or obvious correspondence in the RE model since unlike porosity (or saturated moisture content) it is not a static parameter that can be measured a priori as a relationship between pore (void or saturated) space and total (pore plus solid matrix) space. Drainable porosity is a dynamic storage coefficient reflecting the amount of water a given hillslope will drain by gravity under given conditions, and thus depends not only on the hillslope's soil properties but also on its geometry, inclination, antecedent saturation, water table depth, vegetation cover, and the rate and duration of any applied recharge [Bear, 1972; Su, 1995; Tritscher et al., 2000]. In the groundwater and soil science literature connections have been drawn between drainable porosity and parameters such as specific yield, effective porosity, and field capacity, and Vachaud and Vauclin [1975] have pointed out the difficulty of trying to use such storage terms of saturated (aquifer) models based on Dupuit and Boussinesq theory to represent the effects of the unsaturated zone.

[21] Given the complexity, or even ambiguity, of the drainable porosity concept, the approach adopted in this work was to define $f$, for the free drainage scenarios, as the equilibrium (steady state) volume of water drained divided by volume of soil initially saturated with this water, basing these volumes on the RE model results in order to provide a "match" or mass balance consistency between the HSB and $\mathrm{RE}$ model runs. The matching procedure is straightforward and intuitive in the case of free drainage from completely saturated conditions. At steady state the HSB hillslope will have drained completely. For the RE hillslope the water table will likewise have dropped to zero after a given time period $T_{s}$, but some water will remain in the unsaturated zone and the hillslope will continue to drain very slowly and indefinitely. When we plot the cumulative outflow volume from a transient RE simulation run for a very long time period, the volume will increase rapidly to a value $V_{c}$ at the "steady state" time $T_{s}$, after which there is a discernible flattening of the curve. Thus the drainable porosity for the HSB runs is computed as $f=V_{c} / V_{i}$ where $V_{i}$ is the volume of soil (pore space plus solid matrix) occupied by the water at time zero, which in this case is equal to the volume of the hillslope and is equal for both the HSB and RE models, so with this value of $f$ a volume $V_{c}$ will also drain from the HSB hillslope at steady state. In the case of free drainage from a partially saturated hillslope, as we simulate in this paper, we compute the volume $V_{c}$ drained at steady state from the RE hillslope and the initial volume of water in the hillslope, $V_{w}$, which includes water in the saturated, capillary, and unsaturated zones. The equivalent volume of soil completely saturated with this water is given as $V_{i}=V_{w} / \phi$. The drainable porosity for the HSB model can now be calculated as $f=V_{c} / V_{i}=\phi V_{c} / V_{w}$. We note from this expression that, for free drainage scenarios, the drainable porosity cannot exceed the porosity, as expected.
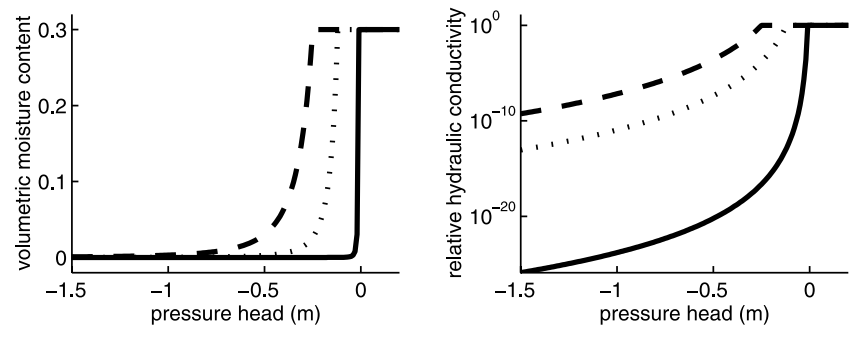

Figure 4. Brooks-Corey $\theta(\psi)$ and $K_{r}(\psi)$ relationships for a sandy loam soil at three different values of the capillary fringe parameter $\psi_{c}:-0.25 \mathrm{~m}$ (dashed line), $-0.12 \mathrm{~m}$ (dotted line), and $-0.01 \mathrm{~m}$ (solid line). 
[22] Applying this calibration or matching procedure to the free drainage scenarios we obtain, for all seven hillslopes and at both 5\% and 30\% slope angles, drainable porosity values very close to the porosity 0.30 (see Table 2 ), most likely because our sandy loam soil has a very fast drainage response with a sharp $\theta(\psi)$ retention curve. We thus used $f=0.30$ for all the intercomparison simulations reported in the next section, and will make additional remarks concerning this parameter in the discussion, presenting also results for a range of $f$ values between 0.10 and 0.30 .

\section{Intercomparison of the HSB and RE Models}

\subsection{Uniform Hillslope}

[23] For uniform hillslopes the HSB model collapses to the classical Boussinesq equation. We use this configuration to examine soil property effects, in terms of the capillary fringe parameter, and to make some preliminary comments on the response of the model under drainage and recharge conditions for different slope angles - the same conditions that will be examined in the following sections for the six nonuniform hillslopes.

[24] For the sandy loam soil type being used in our runs, Figure 4 shows the shape and range of the Brooks-Corey $S_{e}(\psi)$ and $K_{r}(\psi)$ relationships at three different values of the capillary fringe parameter $\psi_{c}:-0.25,-0.12$, and $-0.01 \mathrm{~m}$. Low $\left|\psi_{c}\right|$ values correspond not only to the shortest capillary fringe height but also to the sharpest transition from very dry to completely wet soil, so that storage in the unsaturated zone is smallest and most quickly drained. The intercomparison between the HSB and RE storage profiles and outflow hydrographs for the 5\% hillslope subjected to drainage is shown in Figure 5 for $\psi_{c}=$ $-0.25 \mathrm{~m}$ and $\psi_{c}=-0.12 \mathrm{~m}$. It is quite clear that the match between the HSB and RE models, in both storage and outflow, is closest at low $\left|\psi_{c}\right|$ when the unsaturated storage component is least significant. Indeed for an initial water table height of $40 \mathrm{~cm}$ a capillary height of $25 \mathrm{~cm}$ represents significant additional water storage. It is interesting nonetheless that the shape and timing of the response curves between the two models is broadly similar even at this

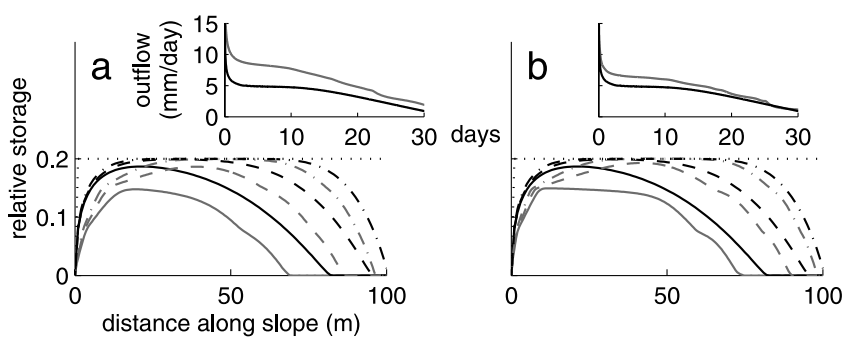

Figure 5. Comparison of the match between HSB (black lines) and RE (red lines) results using (left) $\psi_{c}=-0.25 \mathrm{~m}$ and (right) $\psi_{c}=-0.12 \mathrm{~m}$ for the RE model. Shown are the relative storage profiles along the hillslope and the normalized subsurface flow rates $(\mathrm{mm} /$ day $)$ at the outlet during the drainage run for the uniform hillslope at a $5 \%$ slope angle. For the relative storage plots, dotted line is initial time, $t=0$; dash-dotted line is $\mathrm{t}=2$ days; dashed line is $t=5$ days; and solid line is $t=10$ days. See color version of this figure at back of this issue.

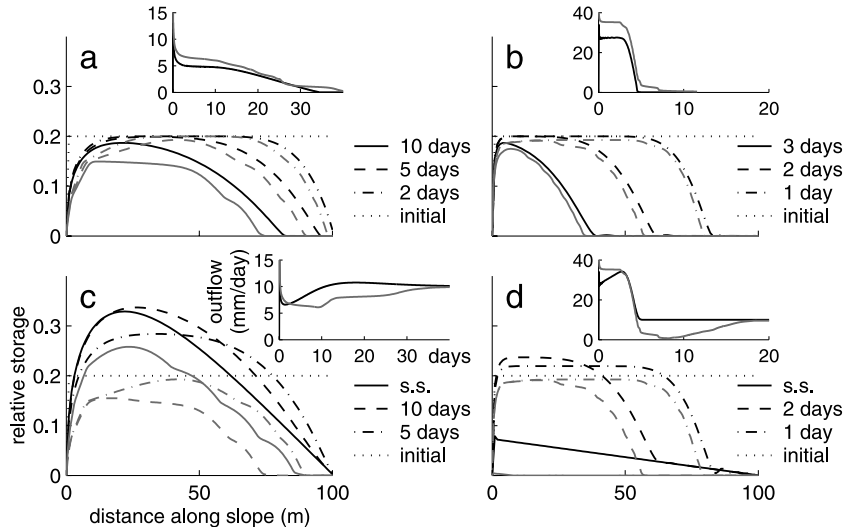

Figure 6. Intercomparison of HSB (black lines) and RE (red lines) relative storage profiles along the hillslope and normalized subsurface flow rates $(\mathrm{mm} /$ day) at the outlet for the uniform hillslope at (left) 5\% and (right) 30\% slope angle under (top) drainage and (bottom) recharge scenarios. For the relative storage plots in the recharge case the solid line is the steady state solution ("s.s."). See color version of this figure at back of this issue.

higher $\left|\psi_{c}\right|$ value, suggesting that a simple correction or extension to the HSB model to account for capillary retention would be a feasible future option, at least for the type of sharp transition soil investigated here. An intercomparison for a soil with a capillary fringe height of only $1 \mathrm{~cm}$ $\left(\psi_{c}=-0.01 \mathrm{~m}\right)$ is not shown, but we would expect an even closer match between the RE and HSB results at this low value. Unfortunately it is the RE model which performs poorly at such low values of $\left|\psi_{c}\right|$, so we were unable to successfully simulate the $1 \mathrm{~cm}$ case. The reason for this is the extreme nonlinearity introduced for such a sharp gradient soil, with an almost jump discontinuity between wet and dry conditions and a drop in relative conductivity of many orders of magnitude over a very narrow pressure head range (see Figure 4). These are typically very difficult problems to simulate, requiring a very fine spatial and temporal discretization and accordingly large computational costs. The numerical difficulty is also apparent on close inspection of Figure 5, where for the same grid discretization the RE model storage and outflow curves are less smooth for $\psi_{c}=$ $-0.12 \mathrm{~m}$ than for $\psi_{c}=-0.25 \mathrm{~m}$. A possible useful implication of these capillary fringe intercomparison results is that the Boussinesq or HSB model would be an accurate and efficient alternative to a Richards equation model precisely under the sort of hillslope or soil conditions for which the RE model is most costly or unreliable.

[25] Figure 6 shows the intercomparison results for 5\% (left) and 30\% (right) slope angles under free drainage (top) and recharge (bottom) scenarios. We obtain a closer match between the two models for the drainage case regardless of slope angle. For the recharge case the water table shapes are in agreement but not their timing, with the RE storage curves consistently lower than those of the HSB model, while the subsurface flow rate for the RE model takes longer to reach its steady state value of $10 \mathrm{~mm} /$ day. Note that the steady state storage profiles for the recharge scenario are independent of initial conditions, as expected. An initial condition corresponding to $20 \%$ of storage 

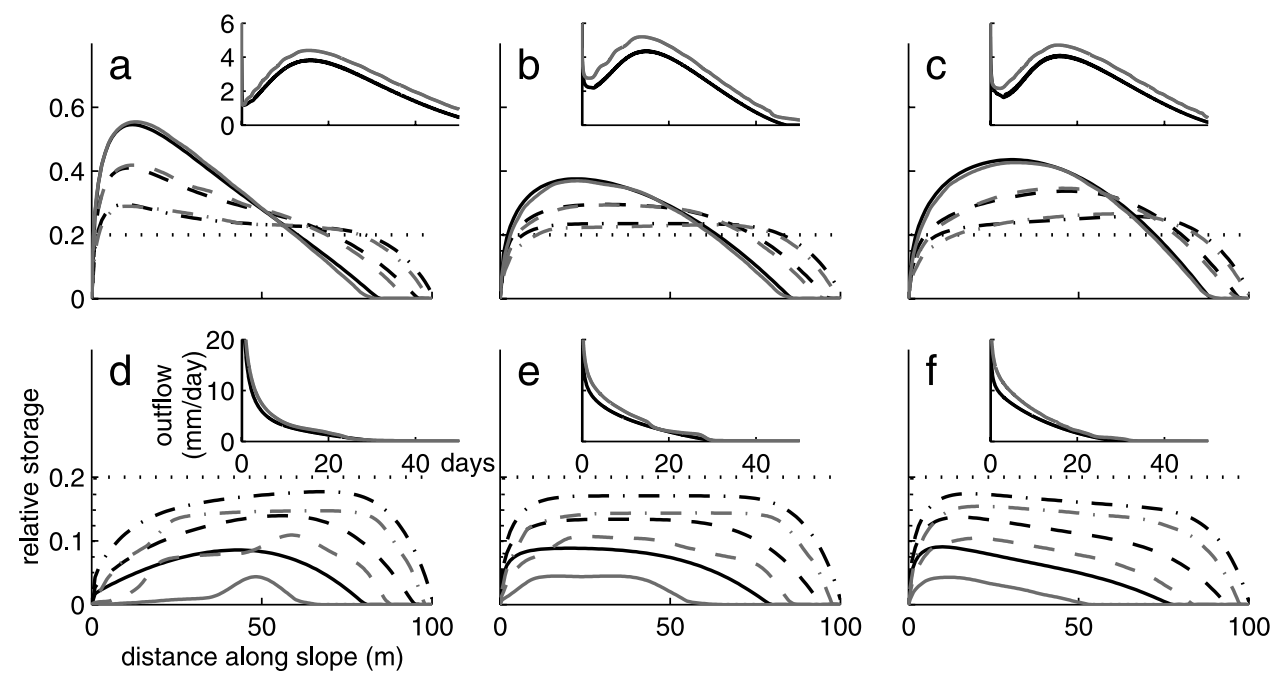

Figure 7. Intercomparison of HSB (black lines) and RE (red lines) relative storage profiles along the hillslope and normalized subsurface flow rates ( $\mathrm{mm} /$ day) at the outlet during the drainage run for the six nonuniform hillslopes at a 5\% slope angle (the labels "a" to " $\mathrm{f}$ " refer to those in Figure 2). For the relative storage plots, dotted line is initial time, $t=0$; dash-dotted line is $t=2$ days; dashed line is $t=5$ days; and solid line is $t=10$ days. See color version of this figure at back of this issue.

capacity here gives the same steady state solution as the initially dry soil used for the HSB model by Troch et al. [2003].

\subsection{Drainage Scenario}

[26] In Figure 7 we analyze the behavior of the models for the six convergent and divergent hillslopes at a 5\% slope angle under free drainage. The matches in outflow rates for all hillslopes, and in storage profiles for the three convergent slopes, are remarkable. The slightly higher subsurface flow rates obtained with the RE model are due to the additional (capillary and unsaturated zone) water contained in the RE hillslopes, an effect similar to what was observed in Figure 5 that showed the influence of the capillary fringe height. For the three divergent slopes, a slower water table drop for the HSB model is observed, but as we saw for the uniform hillslope in Figure 6, the shapes of these storage profiles are in very good agreement. Some numerical artifacts in the RE model results are visible in the form of nonsmooth curves for the storage profiles of hillslopes $\mathrm{d}$ and e and in the early-time outflow behavior of hillslope a.

[27] Figure 8 , for the $30 \%$ hillslope drainage scenario, is qualitatively similar to Figure 7 in terms of the very good agreement between the RE and HSB model subsurface flow and hillslope storage dynamics. The numerical problems in the RE model are reduced in these runs, owing to the finer vertical grid discretization used for the 30\% slopes compared to the $5 \%$ slopes (small wiggles are nonetheless observable in the late-time outflow curves for the three divergent hillslopes). We draw attention to the convergent
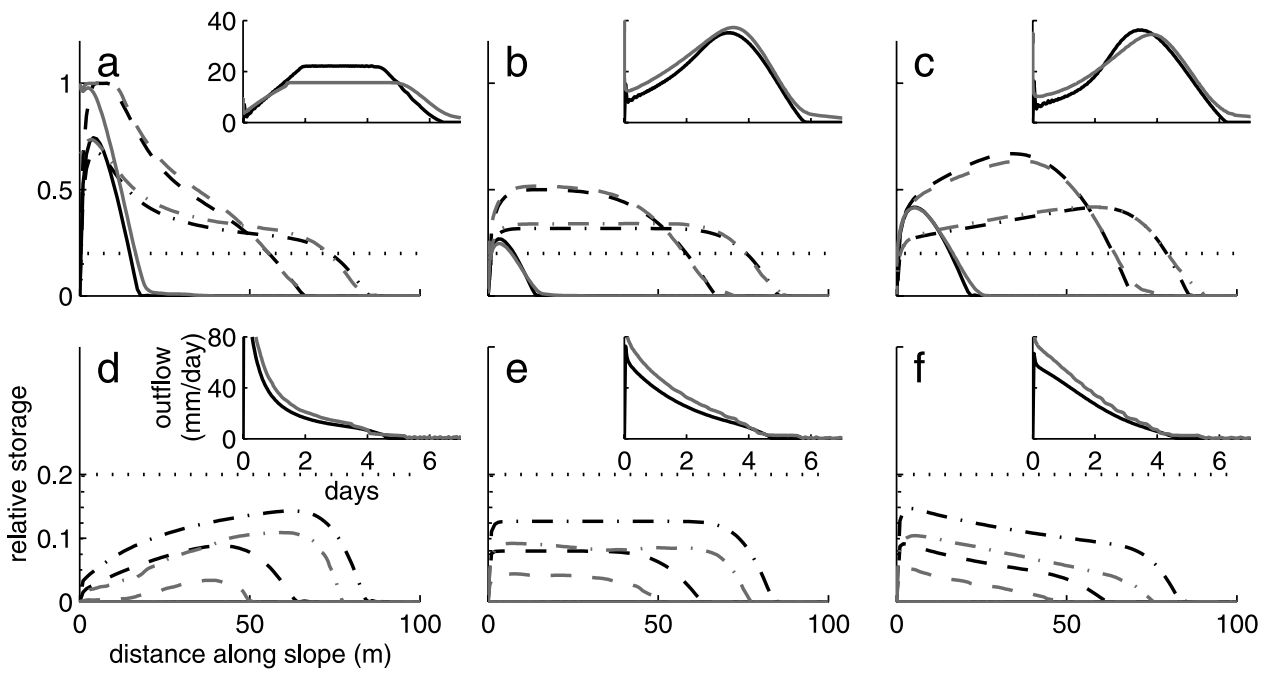

Figure 8. Same as Figure 7 but for the $30 \%$ slope angle. Dotted line is initial time, $t=0$; dash-dotted line is $t=1$ day; dashed line is $t=2$ days; and solid line is $t=5$ days. See color version of this figure at back of this issue. 

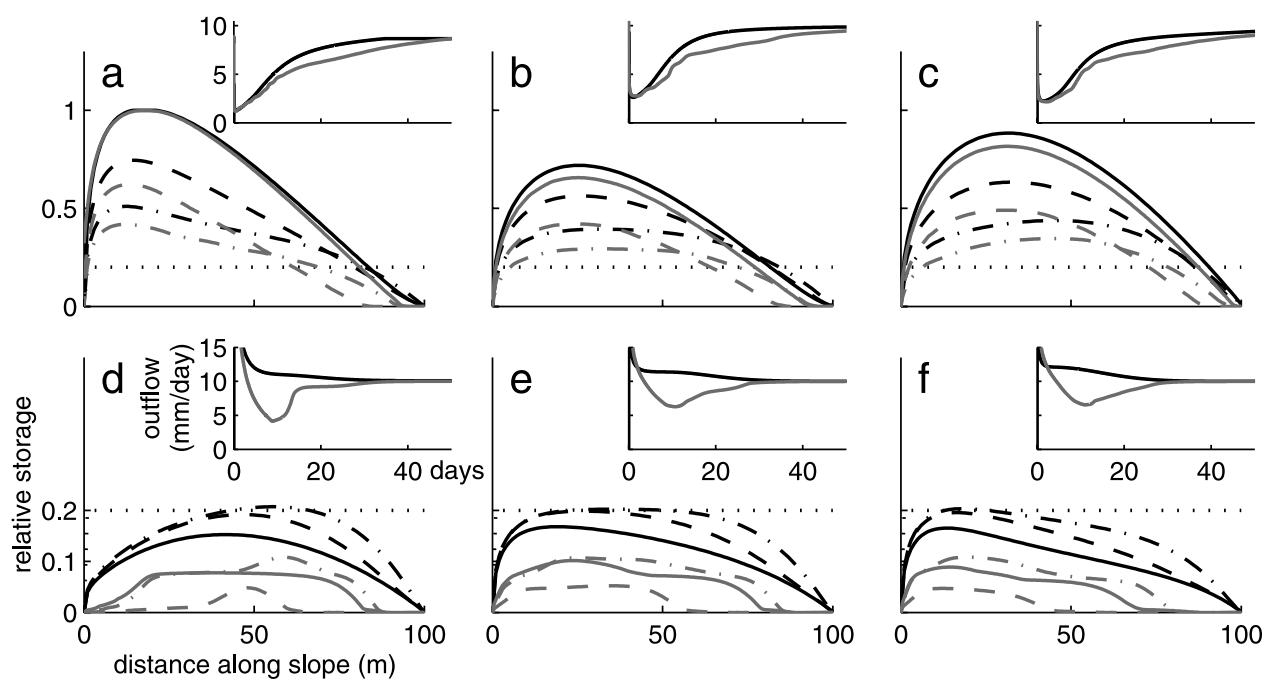

Figure 9. Intercomparison of HSB (black lines) and RE (red lines) relative storage profiles along the hillslope and normalized subsurface flow rates $(\mathrm{mm} /$ day) at the outlet during the recharge run for the six nonuniform hillslopes at a 5\% slope angle (the labels "a" to "f" refer to those in Figure 2). For the relative storage plots, dotted line is initial time, $t=0$; dash-dotted line is $t=5$ days; dashed line is $t=$ 10 days; and solid line is $t=100$ days (steady state). See color version of this figure at back of this issue.

hillslope a where there is clear evidence of surface runoff generation from both the HSB and RE models, seen from the relative storage value of one near the outlet around time $t=2 \mathrm{~d}$ and from the characteristic flat peak in the outflow hydrograph. We note that the volume and spatiotemporal extent of surface runoff is greater for the RE model, probably due to differences in the way the two models handle overland flow (which has not been investigated in this work), and this accounts for the subsurface flow hydrograph having a lower and wider flat peak for the RE model, and for its higher water table elevation near the outlet at time $t=5 \mathrm{~d}$. For the HSB model the volume of overland flow is $55 \mathrm{~m}^{3}$, computed from a mass balance between the initial volume of water in the hillslope $\left(300 \mathrm{~m}^{3}=0.4 f V_{h} / \bar{d}\right.$; see Table 2) and the cumulative subsurface flow volume computed by the model $\left(245 \mathrm{~m}^{3}\right)$. For the RE model the runoff volume computed from the surface boundary conditions is $102 \mathrm{~m}^{3}$, and the surface saturation event occurred from $t=1.78 \mathrm{~d}$ to $t=5.10 \mathrm{~d}$ with a peak extent of the variable source area covering $11.1 \%$ of the hillslope surface at time $t=3.13 \mathrm{~d}$.

\subsection{Recharge Scenario}

[28] The intercomparison of the HSB and RE models for the six nonuniform hillslopes under recharge conditions at $5 \%$ and 30\% slope angles is shown in Figures 9 and 10, respectively. As for the drainage case, there is not a notable difference in the quality of the match obtained at $5 \%$ and $30 \%$, and once again the agreement between the models for the convergent hillslopes is better overall than that for the divergent slopes. The convergent slope a at 30\% inclination generates surface runoff as it did for the free drainage scenario. Unlike the drainage scenario, we observe that the subsurface flow rates from the RE model are now lower than those from the HSB model, and moreover the RE model takes significantly longer to reach the steady state subsurface flux of $10 \mathrm{~mm} /$ day. This suggests a strong role of the unsaturated zone in delaying the transmission of infiltrated water from the surface to the outlet. In addition, the apparent mismatch in cumulative outflow volume between the two models gives an indication of the greater dynamical complexity of recharge simulations compared to free drainage ones, with possible consequences for procedures aimed at "calibrating" the drainable porosity parameter for these cases. As before the relative storage values across the length of each hillslope are lower for the RE model than for the HSB model.

\section{Discussion}

[29] The intercomparison between the hillslope-storage Boussinesq and Richards equation models for various scenarios and hillslope configurations shows that the HSB model is able to capture the general features of the storage and outflow responses of complex hillslopes. Overall, the following broad trends are observed in the matches between the two models: (1) closer match for convergent hillslopes than divergent, with the uniform hillslope in between; (2) equally good (or poor) matches at $5 \%$ and $30 \%$ bedrock slope angles, except as noted below for hillslope a; (3) closer match under drainage conditions than recharge; and (4) remarkably good matches of the diversity of shapes, including peaks and spreads, that characterize the storage and outflow dynamics of the different hillslopes.

[30] The largest deviations in outflow response occur in the recharge scenarios, owing to the role of the RE model's unsaturated zone in slowing the transmission of rainfall through the hillslope soil, in particular for the divergent slopes which attain very dry conditions (and thus low relative hydraulic conductivities) very early in time. Significant deviations also occur for convergent hillslope a at a slope inclination of $30 \%$ for both the drainage and recharge scenarios, where the volume and spatiotemporal extent of surface runoff is greater for the RE model, so the subsurface flow hydrograph has a lower and wider flat peak. In terms of storage profiles, the water table position simulated by the RE model is invariably lower than the corresponding storage measure produced by the HSB model, providing a 

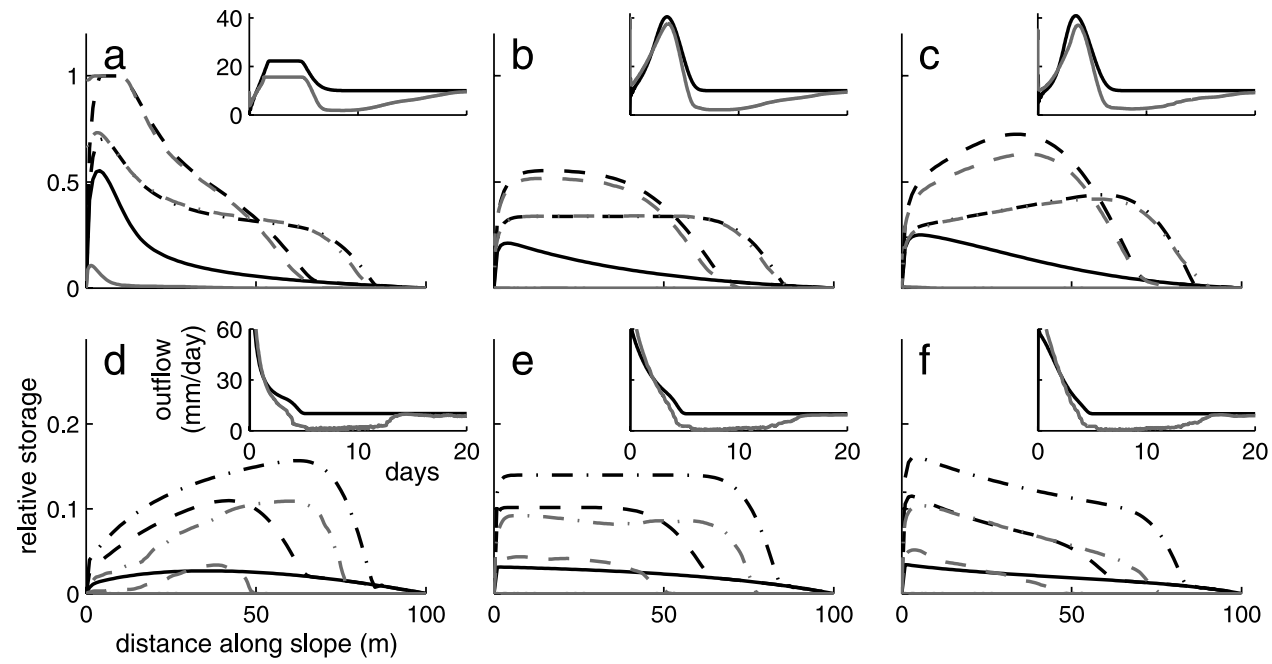

Figure 10. Same as Figure 9 but for the 30\% slope angle. Dotted line is $t=1$ day, dash-dotted line is $t=2$ days; solid line is $t=10$ days, and dashed line is $t=50$ days. Note that for the HSB model, by time $t=10$ days, steady state is reached for all six hillslopes, so in the relative storage profiles the solid and dashed black lines are identical. For the RE model, on the other hand, steady state is not yet reached by time $t=10$ days, and by time $t=50$ days when steady state is reached, all but the convergent hillslope a have a water table height of zero throughout the hillslope; moreover, for the three divergent hillslopes the water table has already dropped to zero by time $t=10$ days. See color version of this figure at back of this issue.

clear indication of the influence of the unsaturated zone. The only notable exception to this behavior is again for the surface runoff-generating $30 \%$ hillslope a, where due to the longer duration and extent of overland flow for the RE model, the water tables at later times remain higher than for the HSB model.

[31] The closer match between the HSB and RE outflow hydrographs for convergent hillslopes is partly due to the fact that these slopes drain more slowly than the uniform and divergent ones, thus remaining relatively more saturated and in this way reducing the impact of the unsaturated zone. For the faster draining divergent hillslopes for which the unsaturated zone plays a relatively more important role, the faster water table drops for the RE model are due to water draining from a larger soil volume that allows partial saturation, as opposed to the HSB model which drains water from a smaller soil depth that is either saturated or dry.

[32] In addition to the remarkably close agreement between the HSB and RE models under specific conditions, the general similarity in the shapes of the outflow and storage profiles produced by the two models for both convergent and divergent hillslope configurations is worth emphasizing because one of the primary aims of the HSB extension to the classical Boussinesq model is to allow, with a simple model, realistic simulation of nonidealized hillslopes of arbitrary geometry. Where the differences between the HSB and RE models are greater, these and future intercomparison tests may be helpful in suggesting adaptations of the HSB model to accommodate factors not properly or fully accounted for.

[33] As an example, Figure 5 provided a preliminary assessment of the importance of the unsaturated zone in subsurface flow as represented by one of the parameters, $\psi_{c}$, commonly used to characterize this zone. Given that for many soils the capillary fringe can represent a quite signif- icant portion of unsaturated storage, this represents an obvious first extension to the HSB model that is currently being pursued. For the classical Boussinesq equation various schemes have been reported for incorporating the capillary zone [e.g., Parlange and Brutsaert, 1987; Fink et al., 2001], and there are many approximate or analytical expressions derived from Richards' equation that could also be used in the future to parameterize unsaturated zone processes into the HSB model. Additional intercomparison tests will be required to better quantify the influence of the unsaturated zone under different scenarios, for instance nonsandy soil types and rainfall/evaporation forcing (wetting-drying cycles). These are important for hysteresis effects and because we can introduce more pronounced interactions between the saturated and unsaturated zones, including growth and shrinkage of the vadose zone and situations where storage in the unsaturated zone does not decrease (or increase) monotonically in time.

[34] Of course differences between the RE and HSB results are not attributable solely to the absence of an unsaturated zone representation in the HSB model. Other significant differences between the models include the mathematical representation of the diffuse drainage term, the nature of the nonlinear coefficients and terms in the two models, and the fact that the HSB model assumes flow only along the bed slope whereas the RE model can resolve more general flow in the vertical and horizontal directions (and in the lateral direction as well, but this can be discounted because we presume that in practice the hillslopes for the HSB model will be defined, or extracted from a digital elevation map, according to the location of natural water divides). These will also necessitate further investigation.

[35] Finally, the treatment of the drainable porosity coefficient and numerical errors in the RE model represent other possible sources of discrepancy between the HSB and RE simulation results. Table 2 reports the hillslope dimensions, 

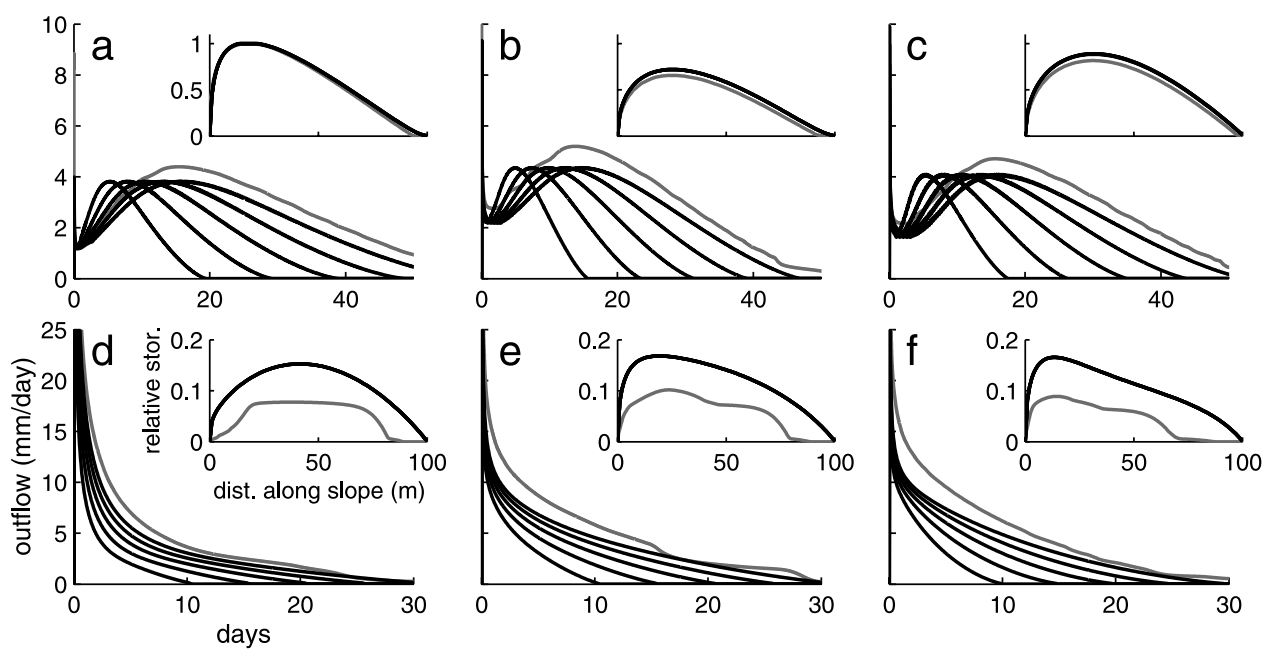

Figure 11. Influence of the drainable porosity parameter $f$ on the subsurface flow behavior of the HSB model. Shown are the outflow curves (mm/day) at the outlet during the drainage run for the six nonuniform hillslopes at a 5\% slope angle using five different values of $f$ (from left to right for each hillslope: $f=0.10,0.15,0.20,0.25$, and 0.30 ). Note that the labels " $\mathrm{a}$ " to " $\mathrm{f}$ " refer to those in Figure 2. The curves for $f=0.30$ and the red lines (RE model) correspond to the outflow results shown in Figure 7. The inset plots show the steady state storage profiles for the recharge scenario and correspond to the $t=100 \mathrm{~d}$ results shown in Figure 9. At steady state the HSB relative storage profiles for all $f$ values collapse onto the same curve. See color version of this figure at back of this issue.

cumulative volume of water drained for the RE and HSB models, initial volume of water in the RE soils, and the drainable porosity values as estimated according to the calibration or matching procedure described earlier (and rounded off to 0.30 in the HSB simulations). The "corrected $V_{H S B}$ " values in this table are a projection of the $0.40 \mathrm{~m}$ of water initially in the HSB hillslopes to the $0.578 \mathrm{~m}$ initially in the RE hillslopes $(0.40 \mathrm{~m}$ saturated zone $+0.12 \mathrm{~m}$ capillary fringe $+0.058 \mathrm{~m}$ unsaturated, noncapillary zone water). It is interesting that even for a soil with such a sharp $\theta(\psi)$ retention curve as our sandy loam, the amount of water above the capillary zone can represent a significant volume of soil water $(10 \%$ of the total initial water volume in this case), and it is for this reason (coupled with the low transmissivity of the soil at low moisture content) that very long simulation times were needed in order to achieve steady state or "complete drainage" in the RE model. The cumulative drained water volumes for the RE and HSB models given in Table 2 show that there is consistency in the volume (or mass) of water drained in the two models, and Figures 11 and 12 confirm that $f=0.30$ gives the best agreement between the HSB and RE models. We note that essentially the effect of an increase in drainable porosity for the HSB model is to increase the cumulative outflow volumes and the time to reach steady state, without altering the peak outflow rate and the steady state relative storage profile.

[36] To give two examples of the numerical difficulties encountered in running the RE model simulations, we observed, for all hillslopes, oscillations in the computed fluxes along the Dirichlet outflow boundary. During the course of the simulation these oscillating fluxes would eventually become opposite in direction (negative during one time step and positive the next), with the magnitude of the positive flux (nonphysical for a draining hillslope) always lower than but converging steadily to that of the negative flux. We partially circumvented this problem by relying on an independent storage-based mass balance estimate to compute the drainage volumes, and by averaging the fluxes over two consecutive time steps to produce the outflow hydrographs. A more rigorous fix would require significant modification of the code or of the hillslope discretization, with possibly large increases in computational requirements (e.g., grid refinement, higher order finite element basis functions, volume-based rather than node-based flux computations). A less significant but no less interesting numerical behavior observed for the RE simulations was an increase in total soil water storage during the free drainage scenarios for a very brief period (e.g., $30 \mathrm{~s}$ for the uniform $30 \%$ hillslope) very early in the simulation. This effect probably reflects an adjustment in the model between imposed initial and boundary conditions that may be discontinuous or otherwise inconsistent (such as the water table at the outlet dropping to zero from an initial positive height due to the outlet boundary condition)

\section{Conclusions}

[37] We have conducted an intercomparison study using a 3-D Richards equation-based numerical model to investigate the soil water storage and subsurface flow response of a recently developed hillslope-storage Boussinesq model on a set of seven hillslopes of convergent, uniform, and divergent plan shape. Our intention was to characterize the similarities and differences in the dynamic behavior of the two models for representative hillslope configurations (plan shape, gentle and steep slope angles, free drainage and rainfall forcing, big and small capillary fringe) in order to better understand the applicability of the simple hillslope- 

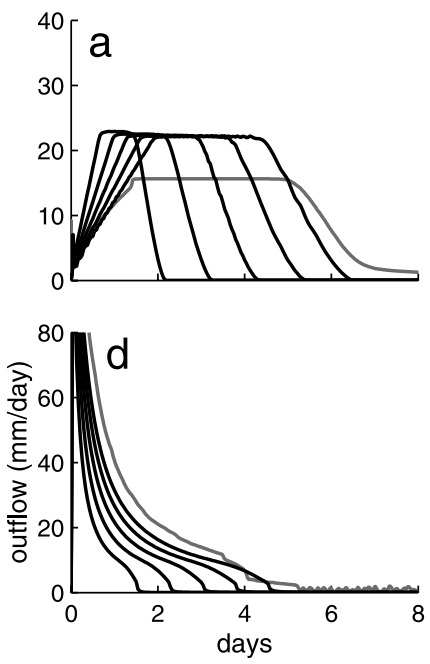
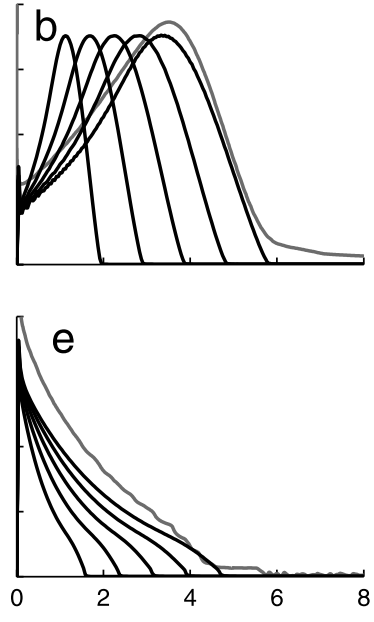
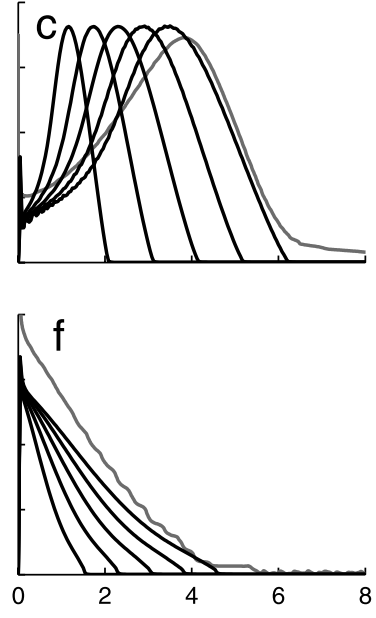

Figure 12. Same as Figure 11 but for the 30\% slope angle and without the inset storage profiles. Also, here the curves for $f=0.30$ and the red lines (RE model) correspond to outflow previously shown, in this case in Figure 8. Moreover, it was verified that even for this slope angle at steady state the HSB relative storage profiles for all $f$ values collapse onto the same curve. For the RE model simulations the steady state water table height is zero for all the hillslopes except for the convergent slope a (see Figure 10). See color version of this figure at back of this issue.

storage concept, to assess, at least in a preliminary manner, the importance of unsaturated zone storage, and to point to future development of the HSB model.

[38] To ensure a consistent framework for the intercomparisons, the setup and discretization of the hillslopes, the imposition of boundary and initial conditions, the correspondence between model parameters, and the sources of numerical error in the RE model were carefully considered. With these aspects adequately handled, the intercomparative assessment could be performed in a reasonably objective manner, shedding light on the relative importance of key hydrological and mathematical differences between the HSB and RE models. Considering that a one-dimensional storage model is being proposed to represent subsurface flow processes in complex (3-D, variable saturation) hillslopes, we observed generally good agreement between the two models over the wide range of scenarios simulated. The best matches in outflow hydrographs were obtained for the free drainage scenarios, indicating the important role that transmission of water through the unsaturated zone plays under recharge conditions. In terms of spatiotemporal water table response, the best matches were observed for convergent hillslopes, with the RE model yielding consistently lower water tables for the divergent slopes. The bedrock slope angle was not found to greatly influence the quality of the RE-HSB match, a finding that in some way corroborates the conjecture made by Troch et al. [2003] concerning the greater impact of plan shape over slope angle in controlling the dynamic behavior of hillslope models. Overall we found that the HSB model was able to successfully capture, in all cases, at least the shapes of the storage and outflow profiles as influenced by atmospheric (recharge or simple drainage), topographic (slope angle), and geomorphologic (hillslope plan shape) factors.

[39] Several avenues can be mentioned for future intercomparison studies aimed at further development of the HSB model. The response of the HSB model will need to be assessed for soil types with broader pore size distributions and different soil moisture retention and wetting/drying characteristics, in order to investigate more thoroughly the influence of the unsaturated and capillary zones. Hillslope configurations involving variations in the ratio of soil depth to soil length and different profile curvatures (concave, straight, and convex) will provide more information on the role of the aquifer's geometric properties. Finally, the search for and validation of simplified formulations of the HSB model, involving linearizations and possible analytical solutions, will benefit from detailed intercomparisons with the full HSB and other hydrological models.

[40] Acknowledgments. This work has been supported in part by Delft Cluster (project DC-030604), the European Commission (contract EVK1-CT-2000-00082), and the Italian Ministry of the University (project ISR8, C11-B).

\section{References}

Bear, J., Dynamics of Fluids in Porous Media, Dover, Mineola, N. Y., 1972. Beven, K., Rainfall-Runoff Modelling: The Primer, John Wiley, Hoboken, N. J., 2001.

Bixio, A., S. Orlandini, C. Paniconi, and M. Putti, Physically-based distributed model for coupled surface runoff and subsurface flow simulation at the catchment scale, in Computational Methods in Water Resources, vol. 2, Computational Methods, Surface Water Systems and Hydrology, edited by L. Bentley et al., pp. 1115-1122, A. A. Balkema, Brookfield, Vt., 2000.

Bras, R., Hydrology: An Introduction to Hydrologic Science, AddisonWesley-Longman, Reading, Mass., 1990.

Brooks, R., and A. Corey, Hydraulic properties of porous media, Hydrol. Pap. 3, Colo. State Univ., Fort Collins, 1964.

Chen, Z.-Q., R. Govindaraju, and M. Kavvas, Spatial averaging of unsaturated flow equations under infiltration conditions over areally heterogeneous fields: 2. Numerical simulations, Water Resour. Res., 30, 535-548, 1994

Fan, Y., and R. Bras, Analytical solutions to hillslope subsurface storm flow and saturation overland flow, Water Resour. Res., 34, 921-927, 1998.

Fink, J., J.-Y. Parlange, and A. El-Kadi, One last visit to the capillarity correction for free surface flow, Water Resour. Res., 37, 827-829, 2001.

Fipps, G., and R. Skaggs, Influence of slope on subsurface drainage of hillsides, Water Resour. Res., 25, 1717-1726, 1989. 
Freeze, R., Role of subsurface flow in generating surface runoff: 2. Upstream source areas, Water Resour. Res., 8, 1272-1283, 1972.

Grayson, R., and G. Blöschl (Eds.), Spatial Patterns in Catchment Hydrology: Observations and Modelling, Cambridge Univ. Press, New York, 2000.

Hilberts, A., and C. Paniconi, Comparison of a 3-D Richards equationbased model with the hillslope-storage Boussinesq model: A test case for nine characteristic hillslopes, Tech. Rep. CRS4-TECH-REP-01/99, Cent. for Adv. Stud., Res. and Dev. in Sardinia, Cagliari, Italy, 2001.

Hornberger, G., and E. Boyer, Recent advances in watershed modelling, U.S. Natl. Rep. Int. Union Geod. Geophys. 1991-1994, Rev. Geophys., 33, 949-957, 1995

Kim, C., and J. Stricker, Influence of spatially variably soil hydraulic properties and rainfall intensity on the water budget, Water Resour. Res., 32, 1699-1712, 1996.

Loague, K. M., Impact of rainfall and soil hydraulic property information on runoff predictions at the hillslope scale, Water Resour. Res., 24(9), $1501-1510,1988$.

Michaud, J., and S. Sorooshian, Comparison of simple versus complex distributed runoff models on a midsized semiarid watershed, Water Resour. Res., 30, 593-605, 1994.

Ogden, F., and B. Watts, Saturated area formation on nonconvergent hillslope topography with shallow soils: A numerical investigation, Water Resour. Res., 36, 1795-1804, 2000.

Paniconi, C., and M. Putti, A comparison of Picard and Newton iteration in the numerical solution of multidimensional variably saturated flow problems, Water Resour. Res., 30, 3357-3374, 1994.

Parlange, J.-Y., and W. Brutsaert, A capillarity correction for free surface flow of groundwater, Water Resour. Res., 23, 805-808, 1987.

Salvucci, G., and D. Entekhabi, Ponded infiltration into soils bounded by a water table, Water Resour. Res., 31, 2751-2759, 1995.

Shamsai, A., and T. Narasimhan, A numerical investigation of free surfaceseepage face relationship under steady state flow conditions, Water Resour. Res., 27, 409-421, 1991.

Sloan, P., and I. Moore, Modeling subsurface stormflow on steeply sloping forested watersheds, Water Resour. Res., 20, 1815-1822, 1984.

Smith, R. E., C. Corradini, and F. Melone, Modeling infiltration for multistorm runoff events, Water Resour. Res., 29, 133-144, 1993.
Smith, R. E., C. Corradini, and F. Melone, A conceptual model for infiltration and redistribution in crusted soils, Water Resour. Res., 35, 13851393, 1999.

$\mathrm{Su}, \mathrm{N}$., Discussion of "A formula for computation of time-varying recharge of groundwater", J. Hydrol., 171, 195-203, 1995.

Tritscher, P., W. W. Read, and P. Broadbridge, Specific yield for a twodimensional flow, Water Resour. Res., 36, 1393-1402, 2000.

Troch, P., M. Mancini, C. Paniconi, and E. Wood, Evaluation of a distributed catchment-scale water balance model, Water Resour. Res., 29, $1805-1817,1993$

Troch, P. A., C. Paniconi, and E. E. van Loon, Hillslope-storage Boussinesq model for subsurface flow and variable source areas along complex hillslopes: 1. Formulation and characteristic response, Water Resour Res., 39, doi:10.1029/2002WR001728, in press, 2003

Vachaud, G., and M. Vauclin, Comment on "A numerical model based on coupled one-dimensional Richards and Boussinesq equations" by Mary F. Pikul, Robert L. Street, and Irwin Remson, Water Resour. Res., 11, 506-509, 1975

Wigmosta, M., and D. Lettenmaier, A comparison of simplified methods for routing topographically driven subsurface flow, Water Resour. Res., 35 , $255-264,1999$

Willgoose, G., and H. Perera, A simple model of saturation excess runoff generation based on geomorphology, steady state soil moisture, Water Resour. Res., 37, 147-155, 2001.

Woods, R., and M. Sivapalan, A synthesis of space-time variability in storm response: Rainfall, runoff generation, and routing, Water Resour. Res. $35,2469-2485,1999$

C. Paniconi, INRS-ETE, Université du Québec, Sainte-Foy, Quebec, Canada G1V 4C7. (claudio_paniconi@inrs-ete.uquebec.ca)

A. G. J. Hilberts, P. A. Troch, and E. E. van Loon, Hydrology and Quantitative Water Management Group, Department of Environmental Sciences, Wageningen University, Nieuwe Kanaal 11, 6709 PA Wageningen, Netherlands. (peter.troch@wur.nl; emiel.vanloon@wur.nl) 


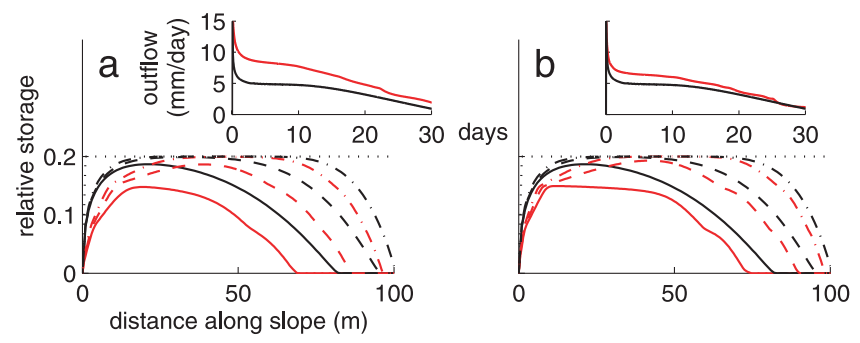

Figure 5. Comparison of the match between HSB (black lines) and RE (red lines) results using (left) $\psi_{c}=-0.25 \mathrm{~m}$ and (right) $\psi_{c}=-0.12 \mathrm{~m}$ for the RE model. Shown are the relative storage profiles along the hillslope and the normalized subsurface flow rates $(\mathrm{mm} /$ day) at the outlet during the drainage run for the uniform hillslope at a $5 \%$ slope angle. For the relative storage plots, dotted line is initial time, $t=0$; dash-dotted line is $\mathrm{t}=2$ days; dashed line is $t=5$ days; and solid line is $t=10$ days.
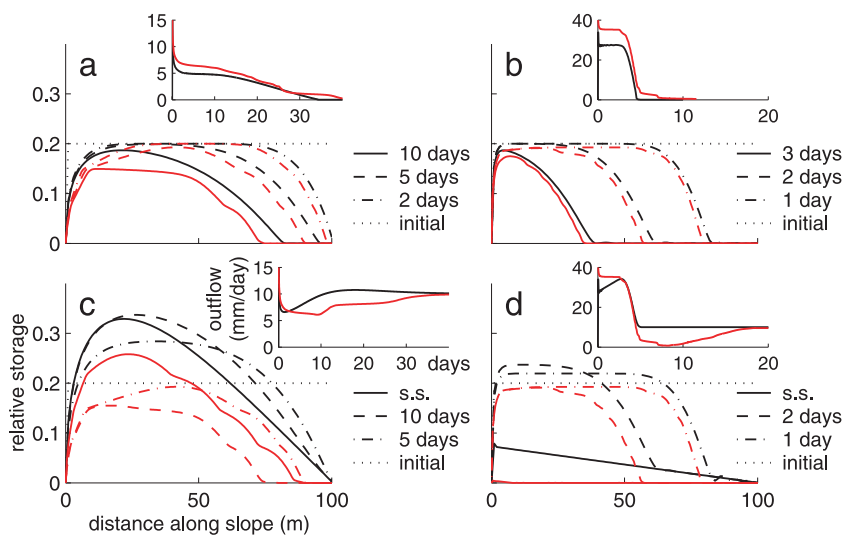

Figure 6. Intercomparison of HSB (black lines) and RE (red lines) relative storage profiles along the hillslope and normalized subsurface flow rates ( $\mathrm{mm} /$ day) at the outlet for the uniform hillslope at (left) $5 \%$ and (right) 30\% slope angle under (top) drainage and (bottom) recharge scenarios. For the relative storage plots in the recharge case the solid line is the steady state solution ("s.s."). 

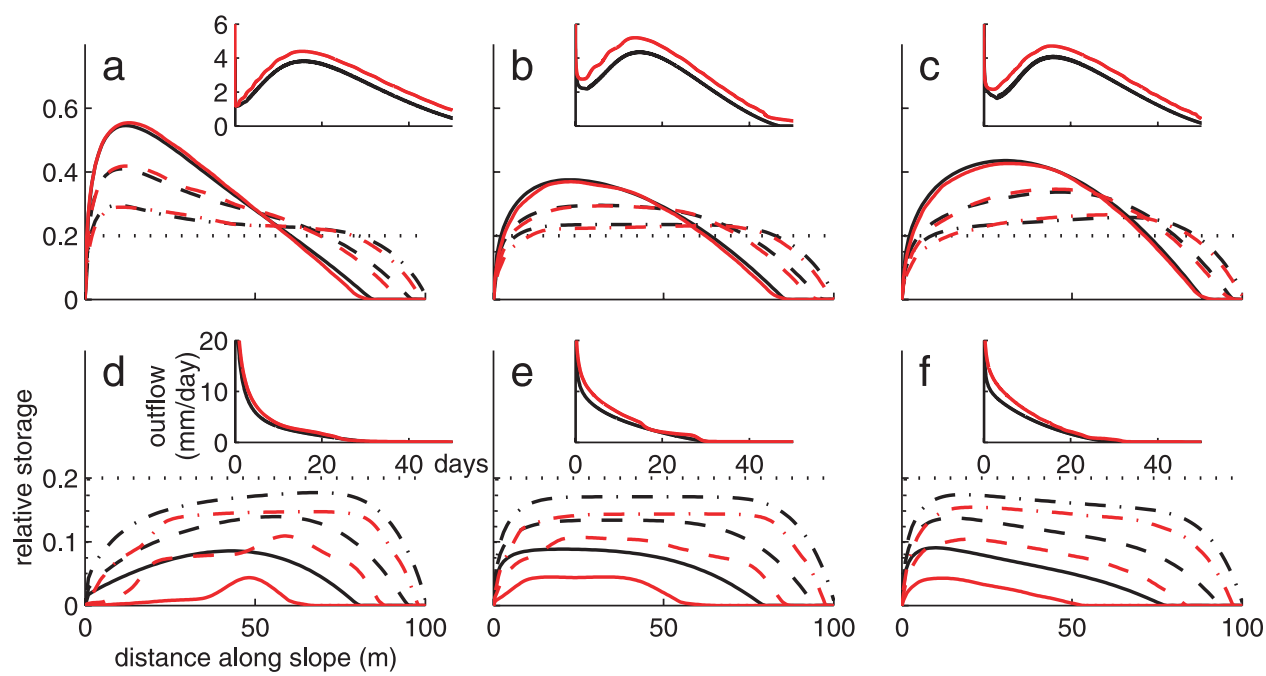

Figure 7. Intercomparison of HSB (black lines) and RE (red lines) relative storage profiles along the hillslope and normalized subsurface flow rates ( $\mathrm{mm} /$ day) at the outlet during the drainage run for the six nonuniform hillslopes at a 5\% slope angle (the labels "a" to "f" refer to those in Figure 2). For the relative storage plots, dotted line is initial time, $t=0$; dash-dotted line is $t=2$ days; dashed line is $t=5$ days; and solid line is $t=10$ days.
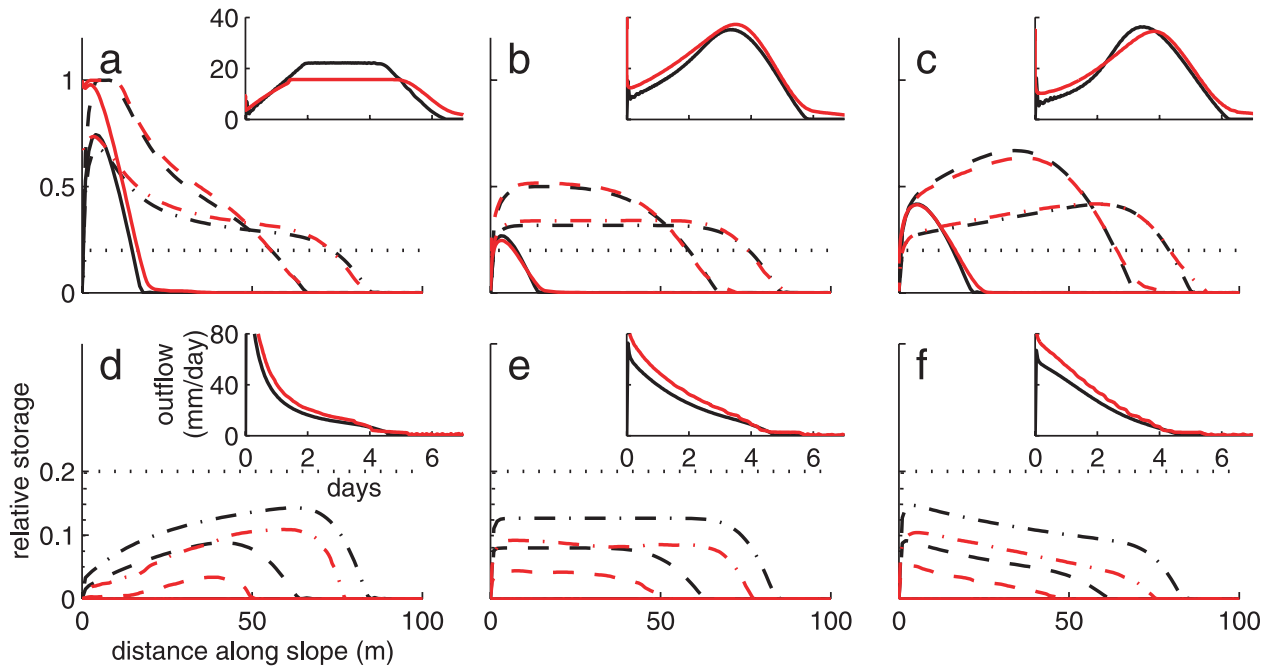

Figure 8. Same as Figure 7 but for the 30\% slope angle. Dotted line is initial time, $t=0$; dash-dotted line is $t=1$ day; dashed line is $t=2$ days; and solid line is $t=5$ days. 

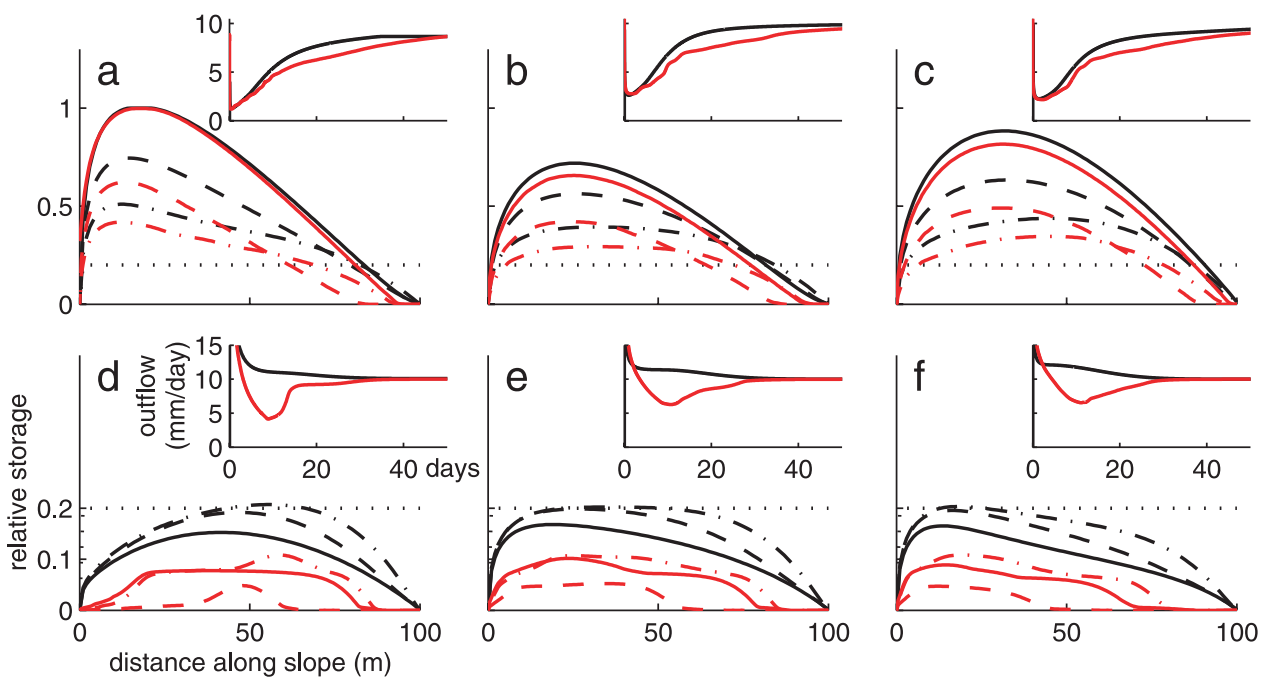

Figure 9. Intercomparison of HSB (black lines) and RE (red lines) relative storage profiles along the hillslope and normalized subsurface flow rates $(\mathrm{mm} /$ day) at the outlet during the recharge run for the six nonuniform hillslopes at a 5\% slope angle (the labels "a" to "f" refer to those in Figure 2). For the relative storage plots, dotted line is initial time, $t=0$; dash-dotted line is $t=5$ days; dashed line is $t=10$ days; and solid line is $t=100$ days (steady state).
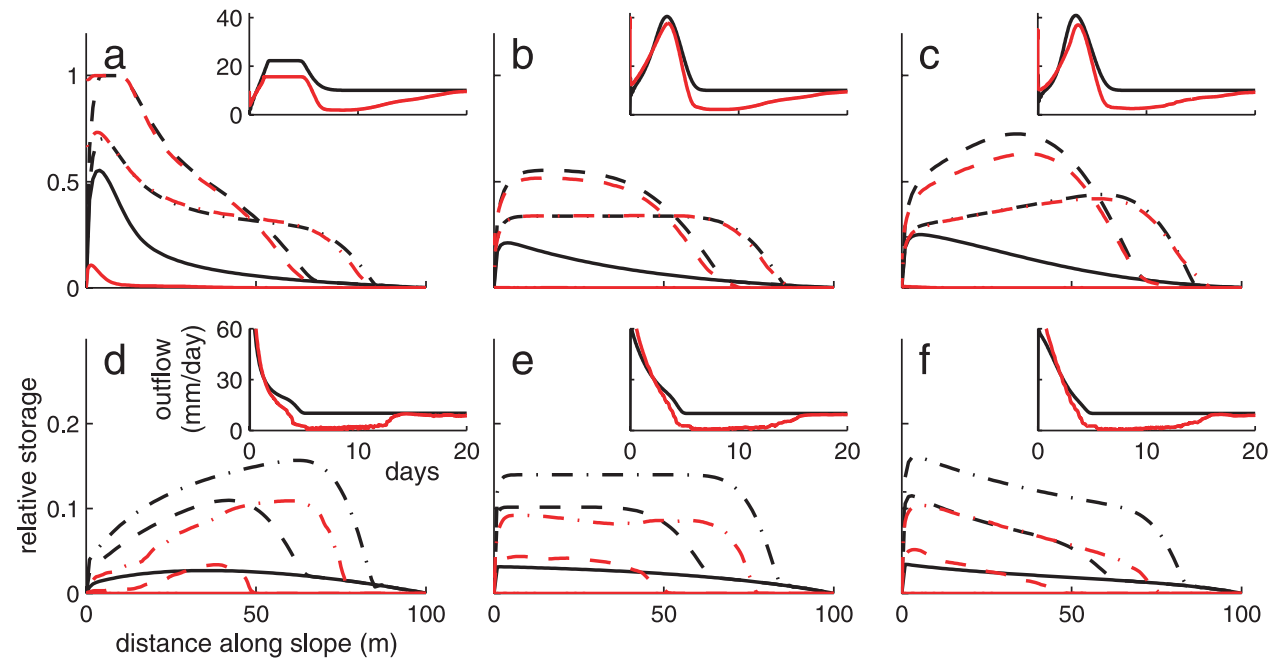

Figure 10. Same as Figure 9 but for the $30 \%$ slope angle. Dotted line is $t=1$ day, dash-dotted line is $t=$ 2 days; solid line is $t=10$ days, and dashed line is $t=50$ days. Note that for the HSB model, by time $t=$ 10 days, steady state is reached for all six hillslopes, so in the relative storage profiles the solid and dashed black lines are identical. For the RE model, on the other hand, steady state is not yet reached by time $t=10$ days, and by time $t=50$ days when steady state is reached, all but the convergent hillslope a have a water table height of zero throughout the hillslope; moreover, for the three divergent hillslopes the water table has already dropped to zero by time $t=10$ days. 

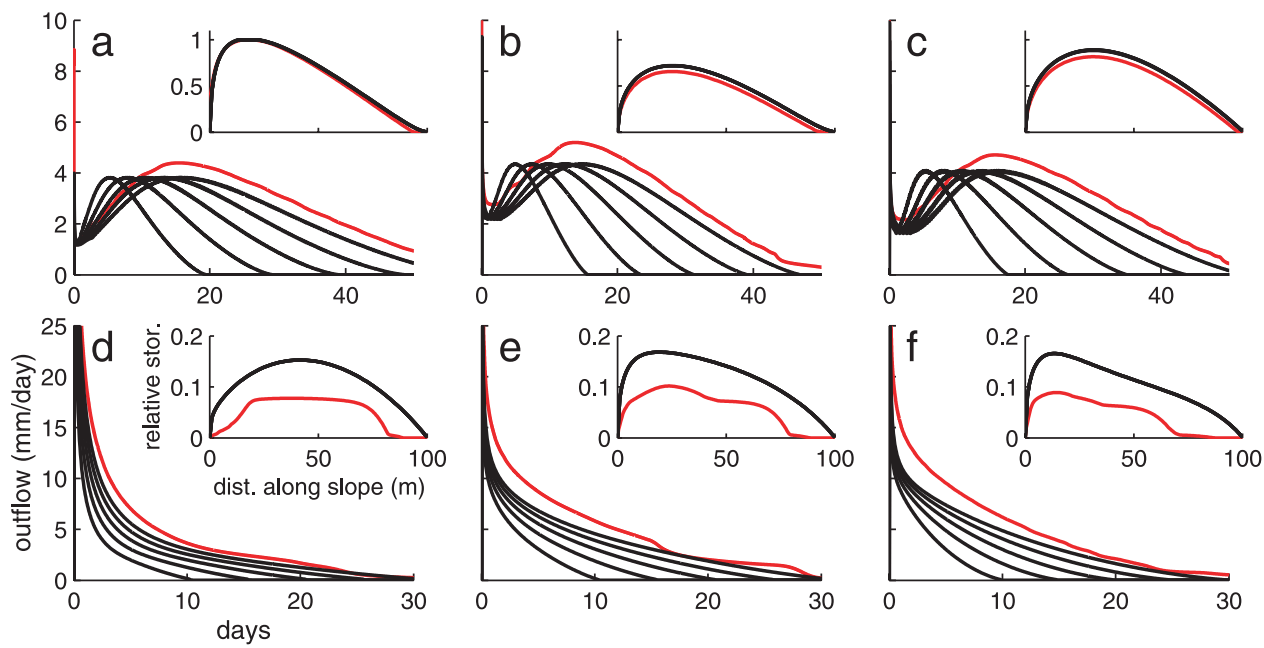

Figure 11. Influence of the drainable porosity parameter $f$ on the subsurface flow behavior of the HSB model. Shown are the outflow curves (mm/day) at the outlet during the drainage run for the six nonuniform hillslopes at a 5\% slope angle using five different values of $f$ (from left to right for each hillslope: $f=0.10,0.15,0.20,0.25$, and 0.30 ). Note that the labels "a" to "f" refer to those in Figure 2). The curves for $f=0.30$ and the red lines (RE model) correspond to the outflow results shown in Figure 7. The inset plots show the steady state storage profiles for the recharge scenario and correspond to the $t=$ $100 \mathrm{~d}$ results shown in Figure 9. At steady state the HSB relative storage profiles for all $f$ values collapse onto the same curve.
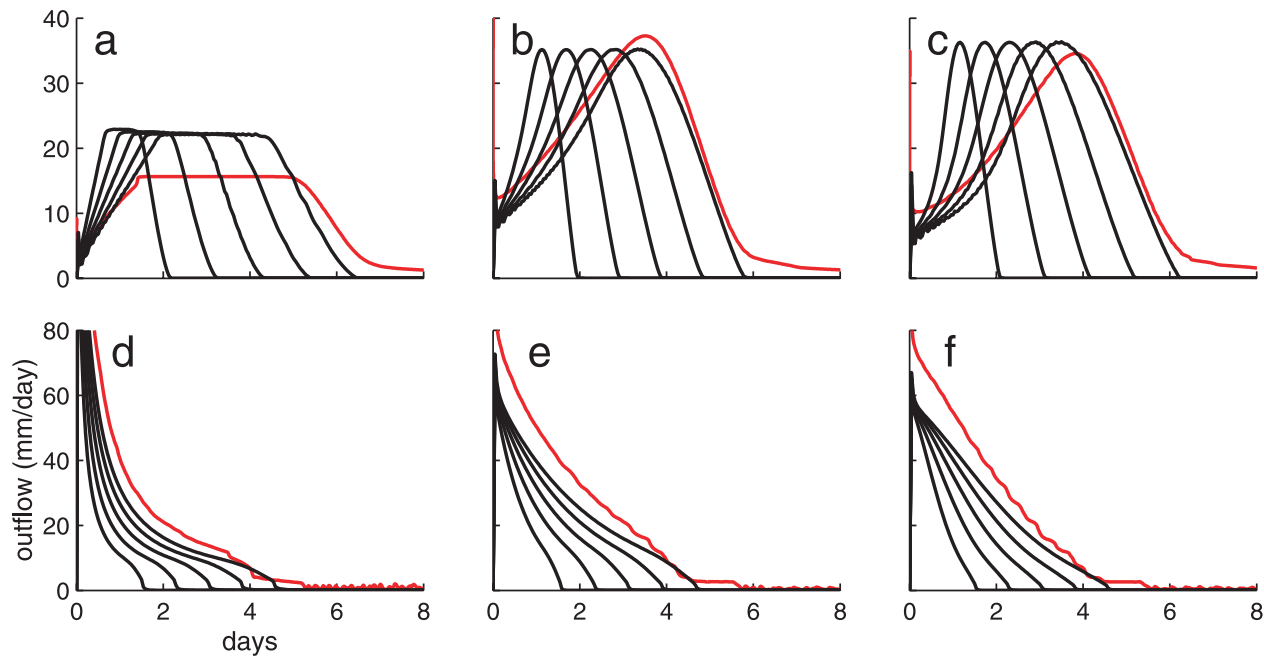

Figure 12. Same as Figure 11 but for the $30 \%$ slope angle and without the inset storage profiles. Also, here the curves for $f=0.30$ and the red lines (RE model) correspond to outflow previously shown, in this case in Figure 8. Moreover, it was verified that even for this slope angle at steady state the HSB relative storage profiles for all $f$ values collapse onto the same curve. For the RE model simulations the steady state water table height is zero for all the hillslopes except for the convergent slope a (see Figure 10). 